\title{
Is the choice of conservation measures influenced by the targeted natural habitats? The case of French coastal Natura 2000 sites
}

\author{
Duhalde Michel ${ }^{1,{ }^{*}}$, Levrel Harold ${ }^{1,2}$, Guyader Olivier ${ }^{1}$
}

${ }_{1}^{1}$ UMR 6308 AMURE, IUEM, Rue Dumont d'Urville, F-29280, Plouzané, France

${ }^{2}$ UMR 8568 CIRED, 45 bis avenue de la Belle Gabrielle, F-94736, Nogent-sur-Marne, France

* Corresponding author : Michel Duhalde, email address : michel.duhalde64@gmail.com

harold.levrel@agroparistech.fr ; olivier.guyader@ifremer.fr

\begin{abstract}
:
Natura $2000(\mathrm{~N} 2 \mathrm{~K})$ is a European network of protected areas that has grown out of the implementation of the Birds Directive (1979) and the Habitats Directive (1992). To date, the literature focussing on "conservation measures" required by the directives has been scarce. This article contributes to a better understanding of associated practices with regard to these measures in the case of France.

We put forward a quantitative approach based on 1378 "action-sheets" randomly extracted from 113 management documents of French Natura 2000 coastal sites. These action-sheets are considered to be the physical embodiment of the notion of the conservation measure itself. The analysis concentrates on the "type" of the proposed measures, expressed in terms of a 9-category public policy instrument typology.
\end{abstract}

In terms of frequency of quotation, we show the specific expected importance of three instruments: the work of Natura 2000 project managers, ecological/civil engineering, and data production. Awarenessraising is the main expected means to the end of countering harmful practices and detrimental behaviours.

We then propose an exploratory analysis of contextual variables explaining the choice of the type of measure, with an AIC-based procedure of model selection and averaging. The interest of this approach is exemplified by a focus on five explanatory variables reflecting the kind of natural habitats concerned by the measures.

Our results show the specificity of instruments associated with coastal habitats. In particular, whereas coastal terrestrial habitats are statistically managed by physical measures (physical regulation and engineering), methods for managing coastal marine habitats are geared towards, on the one hand, awareness raising and participatory approaches, and on the other, regulatory approaches and an 
integration of Natura 2000 objectives into exogenous institutional frameworks.

The results we obtained shed light on the limits and prospects of the implementation of the Natura 2000 program in the marine environment.

\section{Highlights}

- Conservation measures for French Natura 2000 coastal sites are studied. A quantitative analysis of the factors explaining these measures is carried out. Coastal and marine habitats exhibit clear specificities of management orientations. The marine sites may be more dependent on exogenous institutional frameworks.

Keywords : Natura 2000, Conservation measures, Policy instruments, Coastal, Statistical analysis 


\section{Introduction}

Natura 2000 (N2K) is a network of protected areas referred to as the "cornerstone of Europe's nature conservation policy"1. This network has grown out of the implementation of the Birds Directive (BD) (79/409/EEC) and the Habitats Directive (HD) (92/43/EEC), adopted in 1979 and 1992 respectively. There are consequently two types of Natura 2000 sites, with possible or even perfect overlap : Special Areas of Conservation (SPA) for the Birds Directive, and Special Areas of Conservation (SAC). Its objective is to protect habitats and species that are threatened, vulnerable, rare or endemic, and as such are listed in the directive appendices. On 1 January 2014, the network includes more than 27,384 sites $^{2}$, within a total area of more than 1.1 million $\mathrm{km}^{2}$ covering $18.14 \%$ of the European Union's terrestrial area (Environment Directorate-General, 2015a).

Day-to-day site management is described in outline in HD's article 6. Along with an impact assessment requirement for plans and projects (paragraphs 6.3 and 6.4), Member States "shall establish conservation measures" defined as "appropriate statutory, administrative or contractual measures which correspond to the ecological requirements" (6.1) of habitats and species. These measures can be drafted into management plans and their aim is "to maintain or restore the natural habitats and the populations of species of wild fauna and flora at a favourable status" (art 1 (a)). This paper is a contribution to improving our understanding and knowledge of the practices concerning these conservation measures, using the French case as the platform for the study.

Popescu et al., (2014) have provided an extensive review of the existing literature on Natura 2000 , and propose an analysis based on a series of keywords. They show that "Social and policy" articles are relatively scarce compared to "ecological" articles. More specifically, and perhaps surprisingly, "conservation measures" required, as stated in article 6 of the HD, do not appear to be decisive keywords for this literature. Blicharska et al. (2016) complemented this work with a review of 149 social science publications. They identified a shared conclusion on the importance of adaptation to

\footnotetext{
${ }^{1} \mathrm{http} / / /$ ec.europa.eu/environment/nature/legislation/habitatsdirective/index en.htm

2 http://natura2000.eea.europa.eu/\# viewer
} 
local contexts and quality of public participation, even if they underline the need for more research on the actual outcomes of the latter. Social sciences studied the HD implementation largely from the perspective of national strategies for the HD transposition and network deployment (Alphandéry and Fortier, 2010, 2001; Apostolopoulou and Pantis, 2009; Beunen et al., 2013, 2009; Cent et al., 2013; Ferranti et al., 2014, 2010; Hiedanpaa and Bromley, 2011; Stancioiu et al., 2010; Tsianou et al., 2013; Verschuuren, 2002; Winkel et al., 2015) and/or focused on governance processes and stakeholders' participation and perceptions (Adger et al., 2003; Alphandéry and Fortier, 2010; Apostolopoulou et al., 2012; Beunen and de Vries, 2011; Grodzinska-Jurczak and Cent, 2011; Kamal et al., 2015; Paloniemi et al., 2015; Pinton et al., 2006; Welch-Devine, 2011; Young et al., 2013). These analyses are often based on stakeholders' views gathered through interviews, questionnaires or observations made during debates on the subject. Approaches concentrating on the management regimes deployed on operational Natura 2000 sites are still scarce (Borrass, 2014; Morris et al., 2014; Winter et al., 2014), and are generally based on a limited number of case studies. As far as we know, no systematic and large-scale analysis has yet been published on conservation measures promoted in management plans for Natura 2000 sites, and on the factors influencing these measures. Some analyses of conservation measures have been initiated in the grey literature, but are still limited to case studies or "good practice" example lists (AAMP, 2012; De Blust et al., 2010; European Commission and Olmeda, 2014; Sadeleer and Milieu Ltd., 2009). We believe it is important to understand what shapes conservation measures, with reference to a large sample of sites.

To sum up on the above, our approach aims to provide an analysis of Natura 2000 conservation measures that is supported quantitatively, and to explore the local determinants of the choice of different types of measure (or, put differently, of different policy instruments). The material used for this analysis has been extracted from management plans adopted in coastal and marine French Natura 2000 sites. This information will enable us to explore statistically local factors favouring the promotion of different types of conservation measures in a significant part of the French Natura 2000 network. These factors include, among others, variables related to the ecological targets of the measure, their levels of legal protection, the targeted users, the existence of local funding sources, the composition of the steering committee, the presence of other protected areas or various local socio- 
economic characteristics. For practical reasons, it is not possible to present the results associated to all the factors included in the analysis. We restrain this paper to the results associated to five habitat related factors as presented below. This choice presents a particular interest since, as far as we know, the link, that is potentially intuitive, between specific kinds of habitats on the one hand and specific conservation measures on the other has hardly been systematically explored in the existing literature.

\section{Material and method}

\subsection{The French context for Natura 2000}

Under the terms of European treaties (Art. 288, European Union, 2012), each European Member State defines in its own way the administrative details of its designation and management of the network. This results in a variety of national schemes (Kruk et al., 2010; Van Apeldoorn et al., 2010), but the principle of a specific management plan for each site has been adopted by several countries including France (European Commission and Olmeda, 2014, Appendix 2; Kruk et al., 2010, p. 13). After a politically complicated launch in the 1990's (Alphandéry and Fortier, 2010, 2001; Dubois, 2005), France set up and insisted on fostering a local participatory approach (see Figure 1) (Kruk et al., 2010, pp. 45-46). For each area, the participation takes place within a steering committee ("Comité de pilotage" ou Copil) that brings together various local stakeholders and is responsible for drafting a management plan called a "Document of objectives" (referred to hereafter as Docob). This management plan includes an initial snapshot status of the ecological, institutional and social context of the site. It sets out a 6-year plan for forthcoming conservation measures, and summarises these in a series of "action-sheets". We consider that, in the French case, the action-sheet is the physical embodiment of the notion of HD's conservation measure. Operational action in the field (the implementation of action-sheets) is subsequently supposed to rely on the work of local "N2K project managers", and on the voluntary effort and commitment of the stakeholders involved: this, in terms of administrative procedures, may consist of N2K contracts and charters. Some N2K contracts are part of the Common Agricultural Policy, and are limited to agricultural lands. However other contracts may be signed by forest owners, other private owners, local authorities, associations etc. 


\section{The State designates the site}

\section{The Prefecture ${ }^{1}$ appoints the Steering Committee}

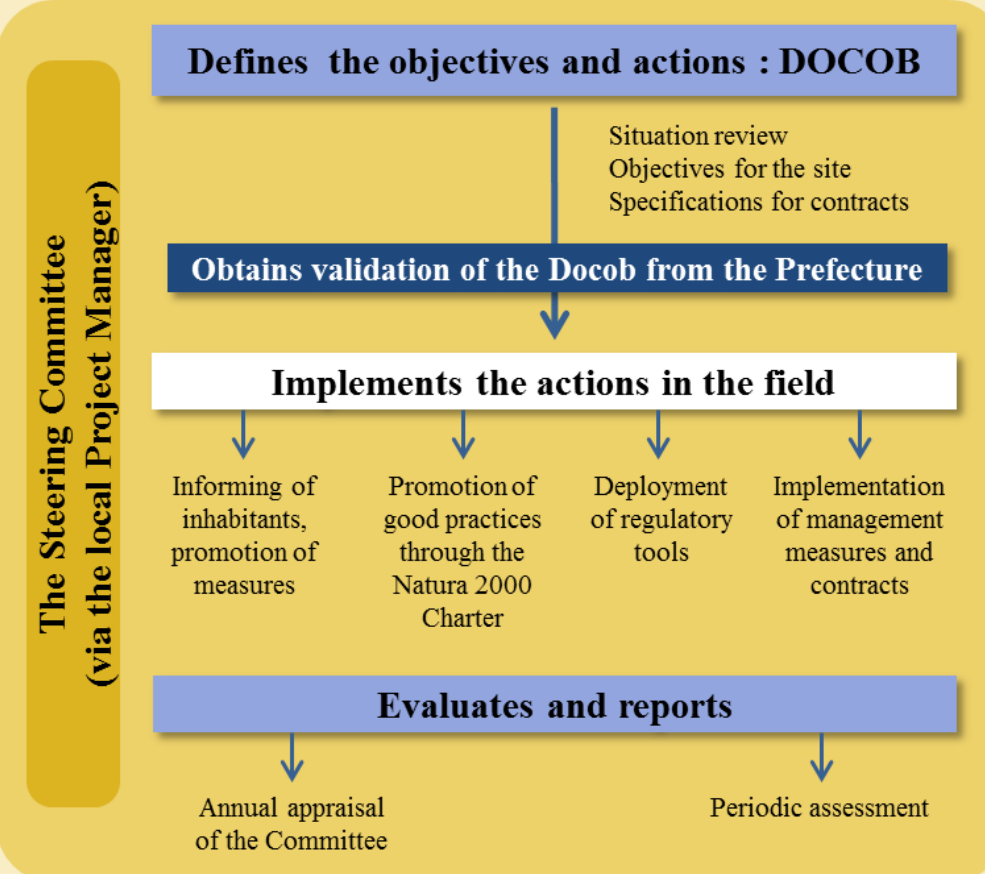

Evaluation by the Commission every six years

${ }^{1}$ Prefecture: local government organisation

Figure 1 : The French process for drafting and implementing a management plan (Docob). Adapted from (Souheil et al., 2011, p. 21)

\subsection{Scope of the analysis and statistical units}

Our study focuses on the coastal and marine part of the French N2K network. Our definition of "coastal sites" covers 322 sites that are partly (sometimes completely) terrestrial. This ensures the capability of our database to provide a marine/terrestrial comparison, without any need to include sites that are "further inland".

A single Docob can manage several sites, in particular when an SPA and a SAC overlap (see Figure 2 for an example in the Mont Saint-Michel Bay).We collected 113 available Docobs, setting out the objectives for the management of 152 of the 1,754 French sites in 2013 (Figure 3). 


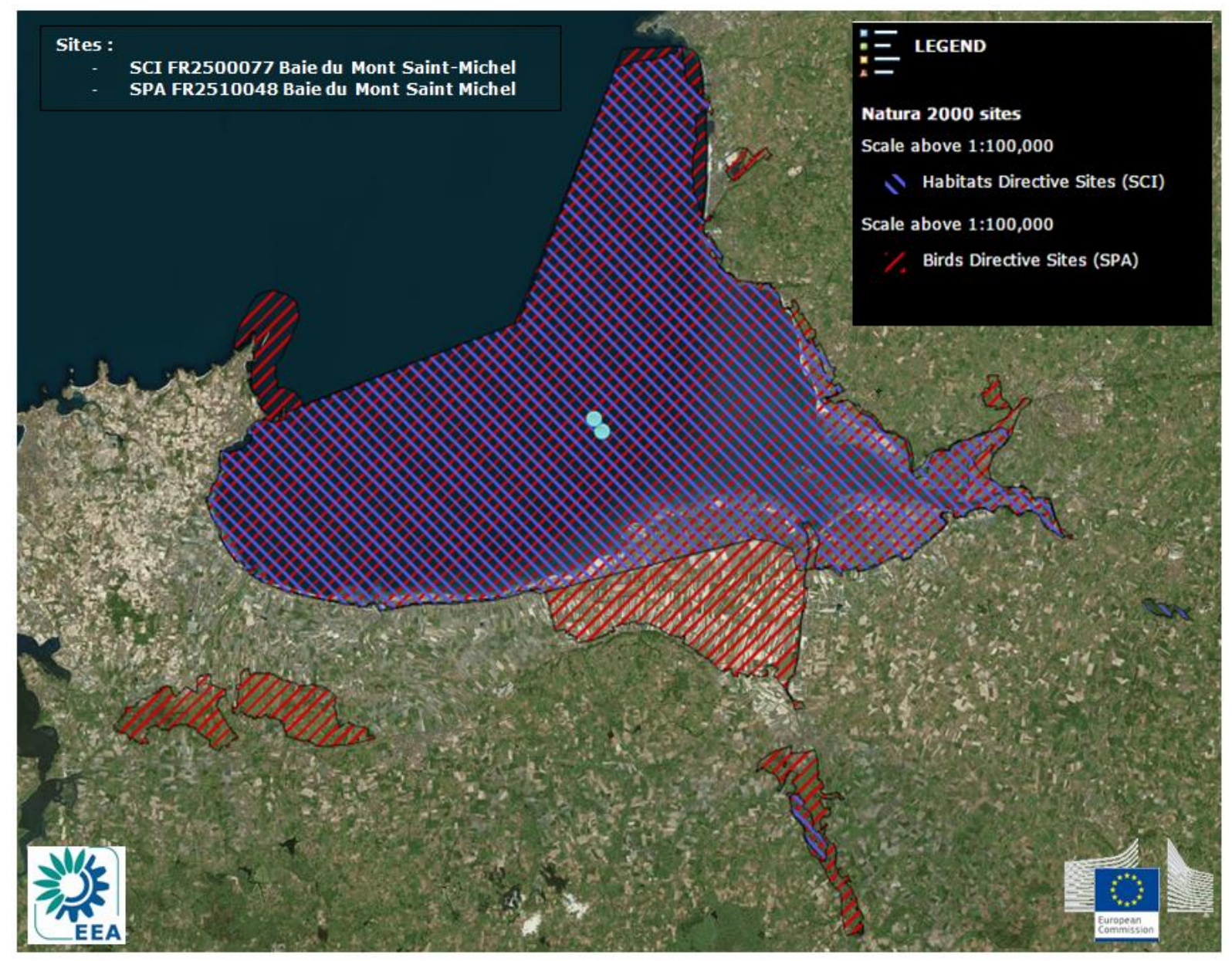

Adapted from Natura 2000 Network Viewer, http://natura2000.eea.europa.eu/ European Environment Agency, (c) European Union, 1995-2015

Figure 2 : Overlapping sites, the example of the Mont-Saint-Michel Bay 


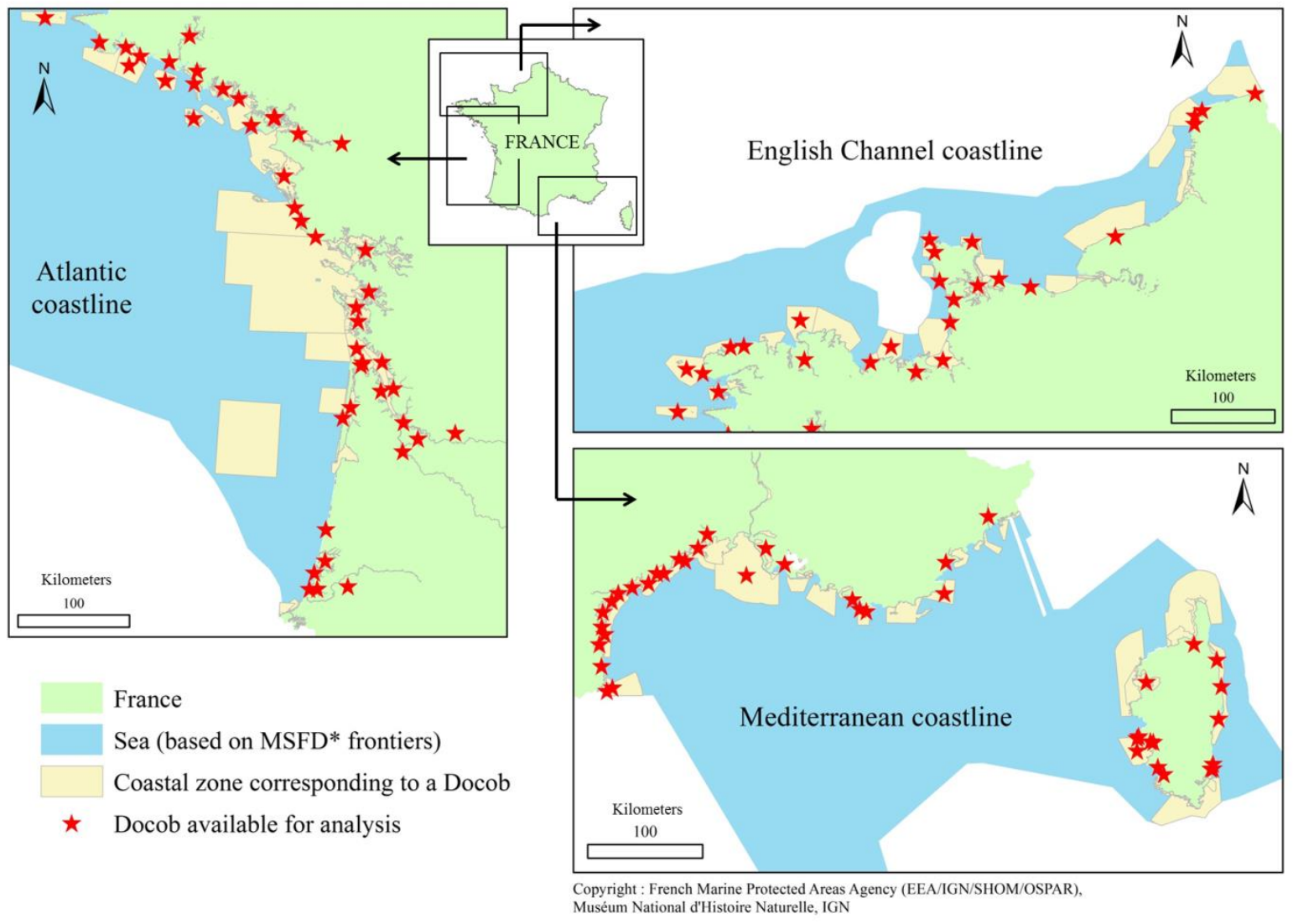

*MSFD : Marine Strategy Framework Directive

Figure 3 Geographic distribution of French coastal sites, pinpointing the Document of Objectives (Docob) available for analysis

Our statistical unit is one action-sheet, extracted from the Docobs (each Docob being explored only once, even if it managed several sites). The Docobs are not standardized to any formal degree. Adaptations were therefore needed in some cases to ensure comparability of analytical units extracted from the different documents ${ }^{3} .25 \%$ of the total number of action-sheets identified were drawn randomly without replacement from each Docob, resulting in a database of 1,378 action-sheets.

The remainder of section 2 details the meaning of our explained variables and the structure of our explanatory models. For a general summary of the methodology, see Figure 4.

\footnotetext{
${ }^{3}$ In addition to the 113 Docobs retained, 12 available Docobs were considered "not comparable" and removed from the analysis.
} 


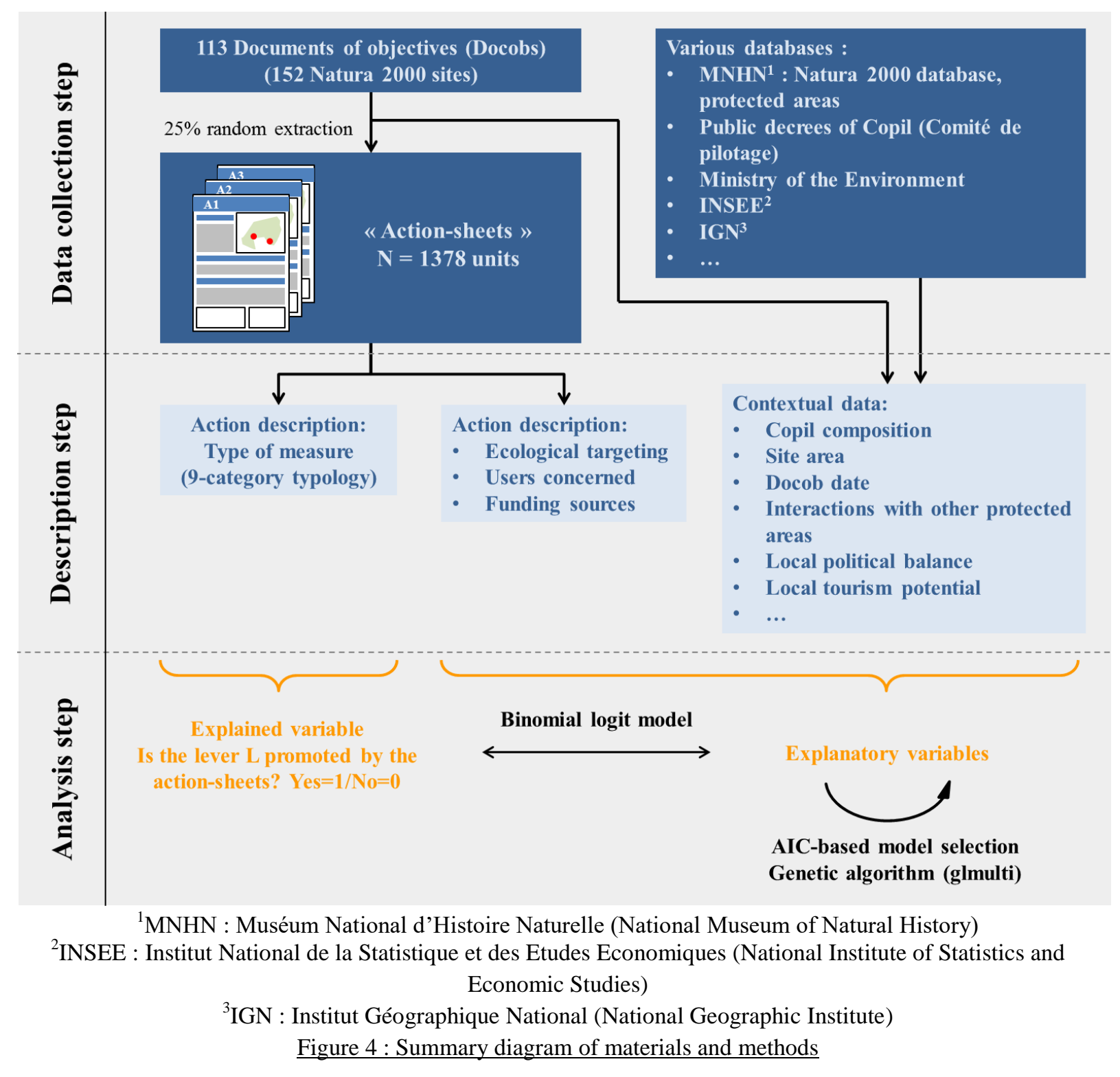

\subsection{Explained variable: a typology of instruments}

This subsection aims to clarify the underlying conventions used to define the different types of conservation measures that we can identify in the Docobs. The notion of "type of measure" can be expressed in terms of public policy instrument. Numerous instrument typologies have been proposed in the literature (Perret, 2010), based on different distinction criteria, for instance government resources (Hood, 2007), political relations and legitimacy (Lascoumes and Le Galès, 2007), or "degree of authoritative force" (Vedung, 1998, p. 34) for the "Carrots, sticks and sermons" typology of (Bemelmans-Videc et al., 1998). Our typology is based on two complementary questions. 
The first one (left-hand side of Figure 5) is "at what level does this measure apply?". This question distinguishes four levels of measure, respectively aimed at improving the knowledge base for future decisions, improving the governance system (Natura 2000 and/or other policies), modifying human pressures and behaviours, or directly modifying the state of the natural environment. These four categories, described in this order, can be seen as a logical sequence of environmental action, ranging from the constitution of preliminary knowledge, to a direct action on the ecosystem. Thus, we highlight the fact that we use in this paper an extended definition of the concept of "conservation measure", in accordance with the nature of the measures frequently encountered in the Docobs.

The second question is (right-hand side of Figure 5) "what is the type of conservation measure adopted?" This question is closer to the notion of "policy instruments" in the sense of what Hood calls "effecting" tools, aimed at modifying behaviours (Hood, 2007, p. 139). In particular, it allows us to refine the third of the above categories, and introduces distinctions close to the spirit of the "carrots, sticks and sermons" trichotomy (Bemelmans-Videc et al., 1998). This second level, with nine different categories, will be the basis of our statistical analysis. Conceptual definitions of these nine categories (or types) of measure are given in Table 1. More details are provided in Appendix A. Table 1 also gives a summary of the range of measures empirically encountered in the Docobs. This summary is consistent with what is observed in terms of conservation measures in coastal areas (Cicin-Sain and Belfiore, 2005; Kindermann and Gormally, 2013) and more generally in environmental policies (Perret, 2010), even if the number of categories and the level of detail of each category vary from one research perspective to another (Vedung, 1998). 


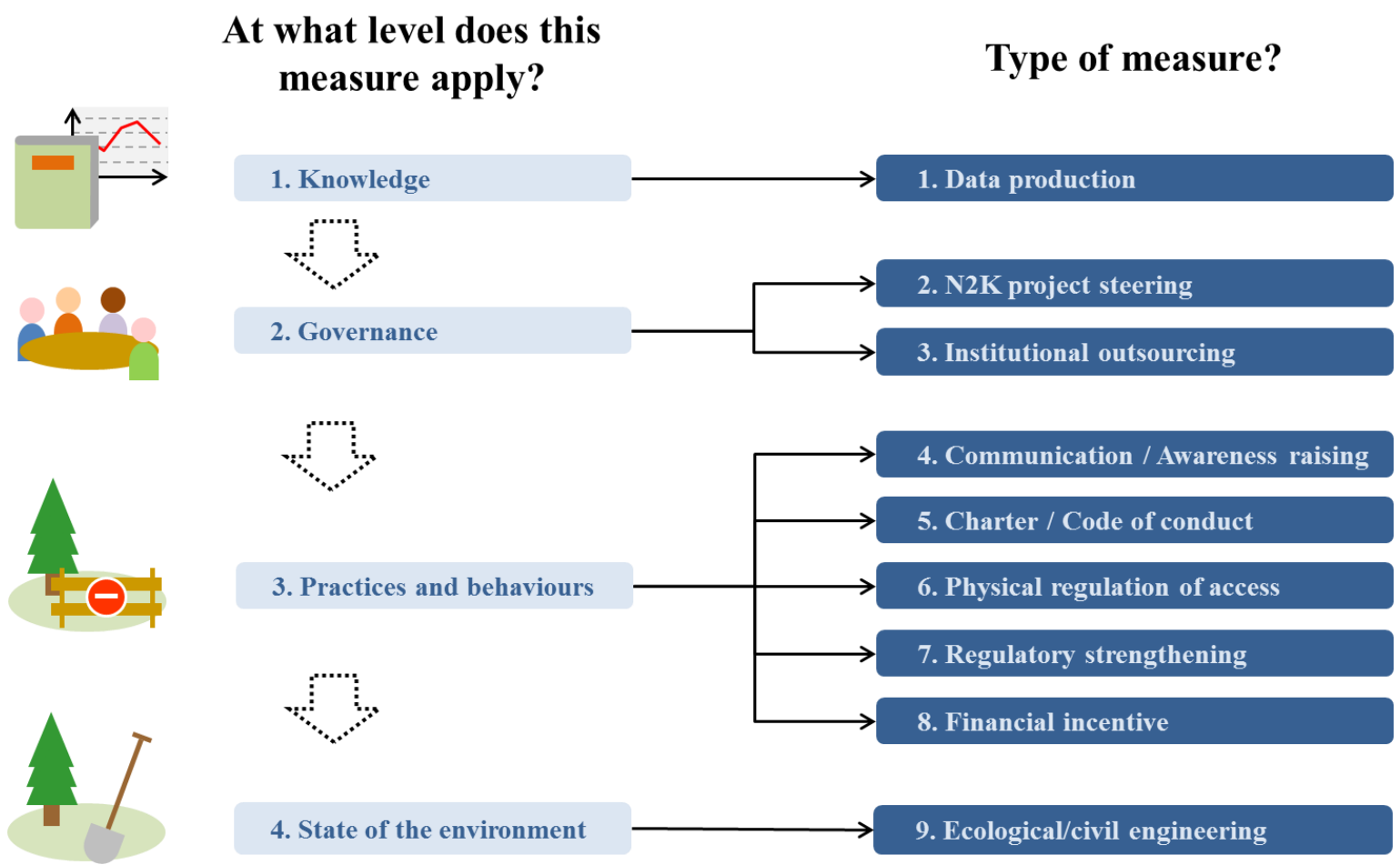

Figure 5: A two-tier typology used to describe the instrumental content of action-sheets

\begin{tabular}{|l|l|}
\hline \multicolumn{1}{|l|}{ Type of measure } & Definition \\
\hline 1. Data production & $\begin{array}{l}\text { Measures aimed at producing information (about usages, about the } \\
\text { environment, or about the link between pressure on, and the state of, the } \\
\text { environment), before actual measures are implemented. }\end{array}$ \\
\hline $\begin{array}{l}\text { 2. N2K project } \\
\text { steering }\end{array}$ & $\begin{array}{l}\text { General steering measures aimed at accompanying the N2K process: meetings } \\
\text { of the Copil and subsequent collective decisions, maintenance of facilities, } \\
\text { specifications and follow-up of other measures, database management, } \\
\text { general dissemination of knowledge. } \\
\text { Primarily used in the absence of a more precise description of one of the other } \\
\text { types a given measure deployed. }\end{array}$ \\
\hline 3. Institutional & $\begin{array}{l}\text { An external institution/organization will be in charge of the conservation } \\
\text { action with regards to other existing public policies, with no explicit } \\
\text { regulatory dimension (e.g. Water policy planning documents, urban planning } \\
\text { documents, management plans of other protected areas...). }\end{array}$ \\
\hline 4. Communication// & $\begin{array}{l}\text { Communication measures aimed at specific user groups having an impact on } \\
\text { the environment, via a range of media (signs, posters, fliers, direct } \\
\text { raising }\end{array}$ \\
\hline
\end{tabular}




\begin{tabular}{|c|c|}
\hline $\begin{array}{l}\text { 5. Charter/code of } \\
\text { conduct }\end{array}$ & $\begin{array}{l}\text { Measures aimed at modifying the behaviour of users through a charter, code } \\
\text { of conduct, code of practice, management specification for eco-labelling. }\end{array}$ \\
\hline $\begin{array}{l}\text { 6. Physical } \\
\text { regulation } \\
\text { access }\end{array}$ & $\begin{array}{l}\text { Measures of "physical" incentive, such as fencing, beacons, markers, } \\
\text { channelling infrastructures... } \\
\text { Users generally remain free to follow the incentive or not. }\end{array}$ \\
\hline $\begin{array}{l}\text { 7. Regulatory } \\
\text { strengthening }\end{array}$ & $\begin{array}{l}\text { Measures aimed at creating or enforcing a regulatory scheme (based on the } \\
\text { underlying idea that the State must define, or has defined, compulsory rules). } \\
\text { This includes policing of environmental regulations. }\end{array}$ \\
\hline $\begin{array}{l}\text { 8. Financial } \\
\text { incentive }\end{array}$ & $\begin{array}{l}\text { Measures aimed at modifying existing practices through a contractual } \\
\text { agreement or financial instrument. Users remain free to follow the incentive } \\
\text { or not. }\end{array}$ \\
\hline $\begin{array}{l}\text { 9. Ecological/civil } \\
\text { engineering }\end{array}$ & $\begin{array}{l}\text { Measures aimed at creating facilities or setting up practices (typically one-off, } \\
\text { but they could also be regularly implemented), which did not exist before, and } \\
\text { are specifically designed to positively modify the state of the natural } \\
\text { environment, or technically mitigate an impact. }\end{array}$ \\
\hline
\end{tabular}

Table $1:$ The 9 types of measure and their definition

Action-sheets often cover a combination of several types of measure. Consequently, we described them in terms of a combination of nine independent Boolean variables, each one indicating if a given type of measure was promoted or not by the sheet. The logical methodological choice was thus to analyze the nine types separately, with a binomial logistic model for each one. "Logit" models have several advantages including a technical simplicity for a first analysis, the broad availability of corresponding software, an abundant supporting literature (Hosmer et al., 2013; Menard, 2001; Rakotomalala, 2014; Sanharawi and Naudet, 2013), and an ability to assess the respective explanatory contribution of the different variables. As the nine instrument categories were not mutually exclusive, it was not straightforward to build a multinomial logistic model. More specific models (nested logit, mixed logit...) have not been explored yet, in contrast to other, better researched, models of choice (for instance, concerning transport modes (Santos et al., 2013)).

Each one of the nine studied types of measure encompasses different administrative devices and on-ground concrete measures. In other words, a given category corresponds to an "ideal-type" of management intervention, for which the action-sheets are seen as reflecting declared preferences of the steering committees. 


\subsection{Explanatory model: an exploratory stance}

We are aware that the management measures of a Natura 2000 site cannot be understood without understanding the multiple dimensions (legal, ecological, sociological, political, historical, economic...) of their local effects. More specifically, we consider that the choice to promote a "type of measure" cannot be mechanically explained by a short series of questions. In this context, our objective is neither to test specific theoretical hypotheses on one or a handful of variables nor to develop a predictive model, but to detect and explain factors that drove the choices of specific types of measure among a wide range of candidate factors.

These potential explanatory variables have different sources. Along with the type of measure (explained variable), some variables were collected from action-sheets: the habitats/species targeted, the uses targeted and the source of funding. Data on the cost of the measure was scarce, and the data there was, took very different forms. Thus, it was not retained as a usable variable. Other data, related to the sites, were gathered from different public sources: the official Natura 2000 database and other data from the National Inventory of the Natural Heritage ${ }^{4}$ (database of protected areas), the National Institute for Statistics and Economic Studies, prefectoral decrees for the composition of Copils, monitoring data from the Ministry of Ecology, electoral data from the Ministry of the Interior, agricultural censuses of the Ministry of Agriculture, complementary data from the Regional Directorate for Environment, the "observatory of regions", the National Geographic Institute (IGN), the Navy's Hydrographic and Oceanographic Department (SHOM), and the French Marine Protected Areas Agency (AAMP). GIS treatments allowed us to establish a link between Natura 2000 sites, the municipalities in which they are based and other types of protected areas. A summary of variables is given in Table 2.

\footnotetext{
${ }^{4}$ Managed by the National Museum of Natural History in France

${ }^{5}$ Managed by the General Commission for the Equality of Regions (CGET)
} 


\begin{tabular}{|c|c|c|}
\hline \multirow{4}{*}{$\begin{array}{l}\text { Variables } \\
\text { relating to } \\
\text { the action- } \\
\text { sheet }\end{array}$} & Category of variables & Proxy of \\
\hline & $\begin{array}{l}\text { Ecological targets, and levels } \\
\text { of legal protection }\end{array}$ & $\begin{array}{l}\text { Technical and institutional possibilities for } \\
\text { measures, level of precision of the measure, } \\
\text { legal pressure for action }\end{array}$ \\
\hline & $\begin{array}{l}\text { Conservation status of the } \\
\text { ecological targets }\end{array}$ & $\begin{array}{l}\text { Urgency of conservation measures, degree of } \\
\text { ecological knowledge }\end{array}$ \\
\hline & Targeted users & Impacting uses identified by the Docob \\
\hline \multirow{8}{*}{$\begin{array}{l}\text { Variables } \\
\text { relating to } \\
\text { the Docob }\end{array}$} & Docob operator & $\begin{array}{l}\text { Involvement of specific stakeholders in Natura } \\
2000 \text {, specific competences for Docob drafting } \\
\text { and implementation }\end{array}$ \\
\hline & Local funding sources & $\begin{array}{l}\text { Local availability of additional funding sources } \\
\text { (associations, local authorities, LIFE funds...) }\end{array}$ \\
\hline & $\begin{array}{l}\text { Composition of the steering } \\
\text { committee }\end{array}$ & $\begin{array}{l}\text { Local system of uses and users, relative political } \\
\text { weights in the decision process }\end{array}$ \\
\hline & $\begin{array}{l}\text { Characteristics of the Docob } \\
\text { (areas, date...) }\end{array}$ & $\begin{array}{l}\text { Technical possibilities for measures, existing } \\
\text { experience from other N2K sites }\end{array}$ \\
\hline & Region & $\begin{array}{l}\text { Influence of the regional network and } \\
\text { administrations on measures }\end{array}$ \\
\hline & $\begin{array}{l}\text { Presence of other protected } \\
\text { areas }\end{array}$ & $\begin{array}{l}\text { Past experience in biodiversity management, } \\
\text { knowledge base, financial and human resources, } \\
\text { local regulatory saturation }\end{array}$ \\
\hline & $\begin{array}{l}\text { Local socio-economic } \\
\text { characteristics }\end{array}$ & $\begin{array}{l}\text { Local economic priorities, inclination to avoid } \\
\text { coercive measures, political pressure for/against } \\
\text { environmental issues }\end{array}$ \\
\hline & $\begin{array}{l}\text { Global ecological content of } \\
\text { the Docob }\end{array}$ & $\begin{array}{l}\text { Overloading of management requirements, } \\
\text { global legal pressure for action }\end{array}$ \\
\hline
\end{tabular}

Table 2: Summary of the potential explanatory variables included in the analysis

The problem of how to select relevant variables to be included in a model is a lively topic of debate, in particular in the field of ecology (Garamszegi, 2011; Ellison et al., 2014; Murtaugh, 2014; Burnham and Anderson, 2014). "Traditional" methods based on Null Hypothesis Testing have been severely criticized (Lukacs et al., 2010; Mundry and Nunn, 2009; Whittingham et al., 2006) and partly replaced by methods based on information theory (Garamszegi et al., 2009; Hegyi and Garamszegi, 2011), although the operational differences between these methods are still being hotly debated (Murtaugh, 2009). We chose to implement an information-theoretical framework (Burnham et al., 2011; Symonds and Moussalli, 2011), because it seemed theoretically sounder to us, and it allowed a comparison of non-nested models, while being easier to compute than a Bayesian analysis ${ }^{6}$ (Posada and Buckley, 2004). More specifically, we used a genetic algorithm based on the Akaike Information Criterion (AIC), consistent with a vision of infinite dimensional truth (Aho et al., 2014). This algorithm was available within the "glmulti" package (Calcagno and De Mazancourt, 2010) under the programming language $\mathrm{R}$ version 3.0.2 ( $\mathrm{R}$ Core Team, 2013). The full details of the methodologies

\footnotetext{
${ }^{6}$ For an interpretation of AIC-based methods as an implicit Bayesian framework, see (Link and Barker, 2006)
} 
used (building and diagnostics of the models, analysis of robustness and of the existence of outliers) are available upon request from the authors.

\section{Results}

\subsection{Statistical content of a Docob}

The frequency with which different types of conservation measures were quoted is shown in Figure 6. As mentioned above, a single action-sheet can promote several types of measure simultaneously (on average, 1.46 measures).

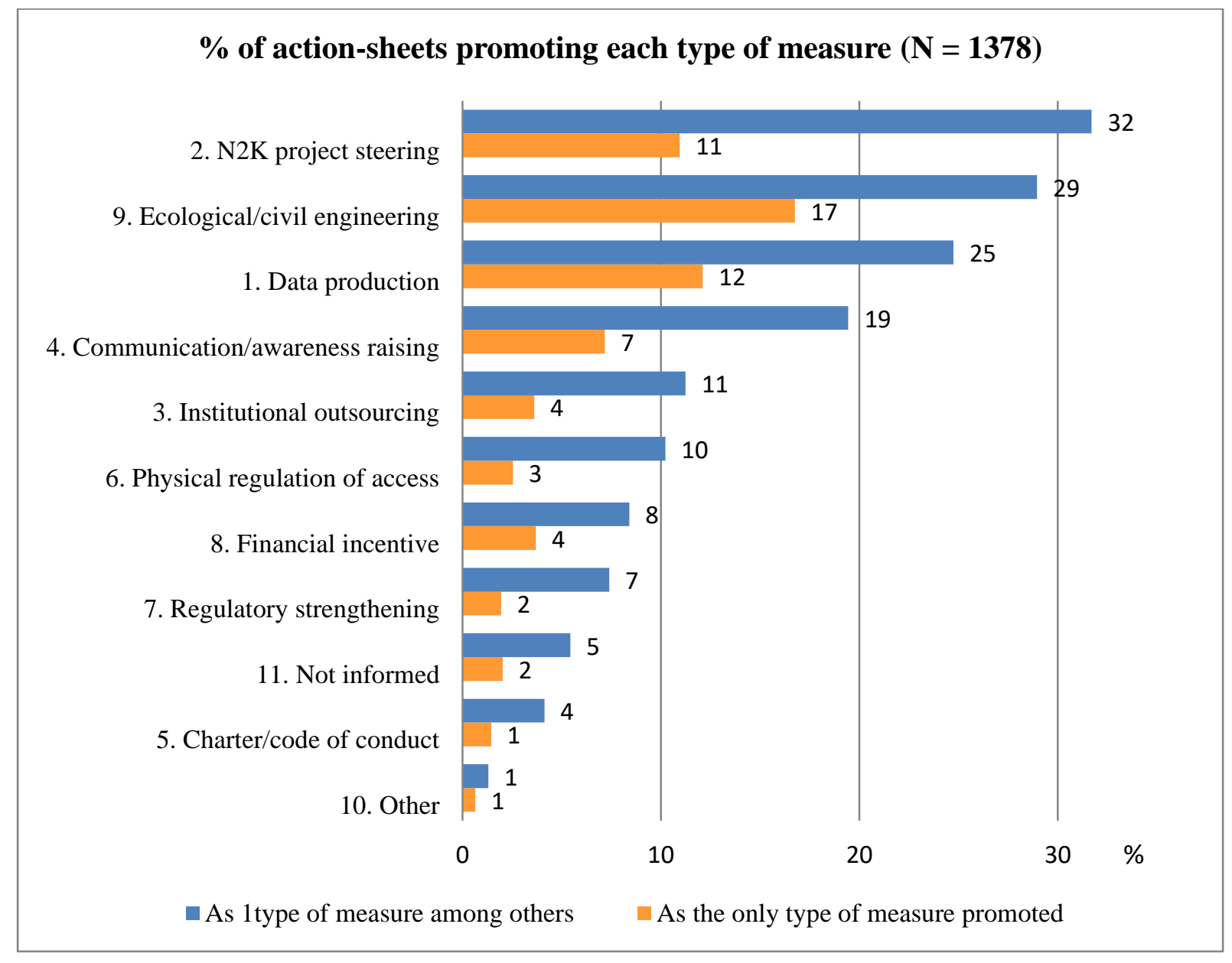

Figure 6: Statistical content of a Docob in terms of types of measure

Figure 6 reveals several significant points.

1. " $2 . \mathrm{N} 2 \mathrm{~K}$ project steering" is the most frequently cited type of measure, as one type of measure among others (represented by the blue bars). This result confirms the expected importance of the project manager work during the implementation phase of the Docob, and notably this includes 
the part they play in nurturing and developing the participatory dimension of the policy. But as a single type of measure (orange bars) this category moves back into third position, showing that it is frequently an accompaniment to other types of measure that need "steering efforts" for their implementation (notably, for the follow-up of results).

2. The types of measure "1. Data production" and "9. Ecological/civil engineering" (technological solutions or direct interventions on the environment) are also frequently cited.

3. Categories 4 to 8 , conceptually classified as trying to modify practices and behaviours, appear to be secondary in terms of frequency, even if "4. Communication" and "6. Physical regulation of access" are in an intermediate position.

4. The data suggest that the Natura 2000 contracts seem to be proposed mostly for ecological engineering purposes (M209), physical regulation of access (M206, based on permanent facilities) or sometimes communication devices (M204), such as information signage, and less frequently as an incentive to change existing impacting practices (M208).

5. The N2K Charter, but also the principle of labelling eco-friendly activities (both included in category 5) don't seem to be considered useful or productive as a type of measure. This could be partly explained by the fact that the N2K Charter exists only since a law was passed in $2005^{7}$. However, many of the Docobs under scrutiny are posterior to that law (see Appendix C).

Table 3 summarizes correlations between the different types of conservation measure.

\begin{tabular}{|l|l|l|l|l|l|l|l|l|}
\hline & M202 & M203 & M204 & M205 & M206 & M207 & M208 & M209 \\
\hline M201 & $0.097 * * *$ & $-0.082 * *$ & $-0.176^{* * *}$ & $-0.077 * *$ & $-0.110^{* * * *}$ & $-0.079 * *$ & $-0.144 * * *$ & $-0.218^{* * *}$ \\
\hline M202 & 1 & -0.021 & -0.035 & -0.001 & $-0.081 * *$ & $-0.062 *$ & $-0.117 * * *$ & $-0.225 * * *$ \\
\hline M203 & & 1 & -0.018 & 0.018 & -0.029 & $0.145^{* * *}$ & -0.025 & $-0.101 * * *$ \\
\hline M204 & & & 1 & -0.010 & $0.221 * * *$ & $0.099 * * *$ & -0.043 & $-0.164 * * *$ \\
\hline M205 & & & & 1 & 0.014 & 0.025 & 0.042 & -0.036 \\
\hline M206 & & & & & 1 & $0.060 *$ & -0.051 & 0.006 \\
\hline M207 & & & & & & 1 & $-0.066 *$ & -0.052 \\
\hline M208 & & & & & & & 1 & -0.009 \\
\hline
\end{tabular}

Table 3: Pairwise Pearson correlation coefficients between types of measure $(\mathrm{n}=1378$; significance: $* 0.95$, ** $\underline{0.99, * * * 0.999)}$

\footnotetext{
${ }^{7}$ Law $\mathbf{n}^{\circ}$ 2005-157 of $23^{\text {rd }}$ February 2005 on the development of rural territories, article 143
} 
These data confirm overall that, at least for coastal sites, it is relevant to detail the concrete "aims" of the triptych "management/contract/charter", and that other forms of intervention are actually promoted, even if only marginally.

\subsection{A focus on the coastal habitat variables}

Many explanatory variables have been taken into account in the analysis and it is not feasible to detail their respective weights in the choice of alternative conservation measures. So in this subsection we will focus on five specific variables to illustrate how it is possible to interpret our results. More specifically, we will examine whether some types of conservation measure seem to be specifically associated with different types of habitats, and in particular coastal habitats. If the existence of different types of conservation measure in different contexts can be inferred from the literature (see for instance Environment Directorate-General, 2015b and Kindermann and Gormally, 2013), as far as we know, a systematic analysis of this link has not been carried out yet.

The different HD habitats are grouped according to the 5-category typology outlined in Appendix B. Table 4 shows the outputs of our models for 5 habitat-targeting explanatory variables. For each type of measure (the rows in the table), we examine whether the different variables of targeted habitats (columns) were identified as being important explanatory variables. We also give their standardized coefficients and the corresponding confidence interval at a level of 5\%. Red cells indicate when the variable is of low importance $(<0.5)$. Green cells indicate when the variable is of high importance ( $>0.5$, but in practice always higher than 0.95$)$. 


\begin{tabular}{|c|c|c|c|c|c|c|}
\hline $\begin{array}{l}\text { Variable } \\
\text { Measure } \\
\text { (Model) }\end{array}$ & & $\begin{array}{c}\text { Coastal } \\
\text { marine } \\
\text { habitats } \\
\text { (HAB_Coastal } \\
\text {.marine) }\end{array}$ & $\begin{array}{c}\text { Coastal } \\
\text { terrestrial } \\
\text { habitats } \\
\text { (HAB_Coastal } \\
\text {.terrestrial) }\end{array}$ & $\begin{array}{c}\text { Freshwater } \\
\text { habitats } \\
\text { (HAB_Freshw } \\
\text { ater) }\end{array}$ & $\begin{array}{c}\text { Terrestrial } \\
\text { non-forest } \\
\text { habitats } \\
\text { (HAB_Terrest } \\
\text { rialnForest) }\end{array}$ & $\begin{array}{c}\text { Forest } \\
\text { habitats }\end{array}$ \\
\hline $\begin{array}{l}\text { 1. Data } \\
\text { production }\end{array}$ & $\begin{array}{l}\text { Imp. } \\
\text { Coef } \\
\text { IC5\% }\end{array}$ & & $\begin{array}{c}0.997 \\
-0.236 \\
{[-0.395 ;-0.077]}\end{array}$ & $\begin{array}{c}0.950 \\
0.142 \\
{[-0.015 ; 0.299]}\end{array}$ & $\begin{array}{c}1.000 \\
-0.295 \\
{[-0.456 ;-0.134]}\end{array}$ & \\
\hline $\begin{array}{l}\text { 2. N2K project } \\
\text { steering }\end{array}$ & $\begin{array}{l}\text { Imp. } \\
\text { Coef } \\
\text { IC5\% }\end{array}$ & $\begin{array}{c}0.975 \\
0.129 \\
{[0.000 ; 0.259]}\end{array}$ & & & & $\begin{array}{c}0.992 \\
-0.184 \\
{[-0.333 ;-0.035]}\end{array}$ \\
\hline $\begin{array}{l}\text { 3. Institutional } \\
\text { outsourcing }\end{array}$ & $\begin{array}{l}\text { Imp. } \\
\text { Coef } \\
\text { IC5\% }\end{array}$ & $\begin{array}{c}0.989 \\
0.217 \\
{[0.035 ; 0.399]} \\
\end{array}$ & $\begin{array}{c}0.061 \\
-0.006 \\
{[-0.034 ; 0.022]}\end{array}$ & & & $\begin{array}{c}0.044 \\
-0.003 \\
{[-0.021 ; 0.014]}\end{array}$ \\
\hline
\end{tabular}

\begin{tabular}{|l|c|c|c|c|c|c|}
\hline 4. Communicati & Imp. & 0.958 & 0.014 & 0.072 & 0.051 \\
on/ awareness- & Coef & 0.155 & $7 \mathrm{e}-4$ & -0.005 & 0.003 \\
raising & IC5\% & {$[-0.002 ; 0.311]$} & {$[-0.003 ; 0.005]$} & {$[-0.029 ; 0.019]$} & {$[-0.012 ; 0.019]$} \\
\hline
\end{tabular}

\begin{tabular}{|l|c|c|c|c|c|c|}
\hline 6. Physical & Imp. & 0.989 & 1.000 & 0.980 & & \\
regulation of & Coef & -0.229 & 0.548 & -0.215 & & \\
access & IC5\% & {$[-0.439 ;-0.019]$} & {$[0.343 ; 0.752]$} & {$[-0.446 ; 0.017]$} & & \\
\hline
\end{tabular}

\begin{tabular}{|l|c|c|c|c|c|c|}
\hline 7. Regulatory & Imp. & 0.982 & 0.967 & 0.972 & & \\
strengthening & Coef & 0.237 & -0.232 & -0.232 & & \\
& IC5\% & {$[0.029 ; 0.444]$} & {$[-0.481 ; 0.016]$} & {$[-0.489 ; 0.034]$} & & \\
\hline
\end{tabular}

\begin{tabular}{|c|c|c|c|c|c|}
\hline $\begin{array}{l}\text { 8. Financial } \\
\text { incentive }\end{array}$ & $\begin{array}{l}\text { Imp. } \\
\text { Coef } \\
\text { IC5\% }\end{array}$ & & & $\begin{array}{c}0.696 \\
0.110 \\
{[-0.108 ; 0.329]} \\
\end{array}$ & $\begin{array}{c}0.133 \\
0.011 \\
{[-0.040 ; 0.062]}\end{array}$ \\
\hline $\begin{array}{l}9 . \\
\text { Civil/ecological } \\
\text { engineering }\end{array}$ & $\begin{array}{l}\text { Imp. } \\
\text { Coef } \\
\text { IC5\% }\end{array}$ & $\begin{array}{c}0.983 \\
-0.142 \\
{[-0.300 ; 0.004]}\end{array}$ & $\begin{array}{c}0.999 \\
0.210 \\
{[0.071 ; 0.349]}\end{array}$ & $\begin{array}{c}1.000 \\
0.326 \\
{[0.202 ; 0.449]}\end{array}$ & \\
\hline
\end{tabular}

Table 4 : The role of "habitats targeting" variables in explanatory models for the choice of types of measure (glmulti outputs).

"Imp." : Importance of the variable among the glmulti 100 best models (cumulated AIC-weight across models). Corresponds to the probability of the variable to be included in the best model within the meaning of KullbackLeibler information theory, given this best model is among those considered.

"Coef" : standardized value of the model-averaged coefficient for the variable.

"IC5\%": confidence interval for the coefficient at the level 0.05 , calculated by glmulti with the method "Lukacs" derived from (Lukacs et al., 2010).

The results of type " 5 . Charter/code of conduct" are deemed unreliable, because of an insufficient number of events per variable, and as such are not presented in the table.

Immediately, we can see that "coastal marine" and "coastal terrestrial" habitats are identified as important explanatory factors (Importance $>0.95$ ) for 6 and 4 types of measure respectively, out of a total of 8 types of measure, whereas other types of habitats have a similar importance only in 7 cases 
out of 24. This is first evidence that there are clearer structural specificities in the management of coastal areas for $\mathrm{N} 2 \mathrm{~K}$.

Another important result that we would like to highlight is that targeting coastal and terrestrial habitats leads to the choice of opposite types of conservation measures, as shown by the plus and minus signs in front of coefficients for types 6,7 and 9 in Table 4.

Concerning "Coastal terrestrial habitats" $(\mathrm{CTH})$, we can see that targeting these habitats has a negative effect on the uptake of "Data production". In other words, statistically speaking, Copils consider ex-ante scientific studies concerning the ecology of habitats and related species, or conducting surveys on the impact of usages on the environment, to be less relevant courses of action to take for these coastal terrestrial habitats. The Copils, in effect, promote other kinds of management measures in preference to these such as "Physical regulation of access" or "Civil/ecological engineering". The first of these types of measures principally involves channelling pedestrian movement by displacing pedestrian footpaths, installing fences, and closing off, or restructuring "wild" carparks. Ecological engineering, on the other hand, may consist of stripping or decompacting the soil, or mechanically controlling alien invasive species (e.g. Cortaderia selloana, Carpobrotus edulis, Spartina alterniflora...). Put differently, these coastal terrestrial habitats are statistically managed by "on-ground" interventions of physical structuring and ecological restoration.

This is a result we would have expected, given that many coastal areas have to deal with tourists traffic that can sometimes be intensive, and that can damage habitats by trampling. If tourists are anonymous one-off visitors, we might expect their impact to be best regulated by permanent facilities. Quite surprisingly though, we can see that additional measures of "Communication/awareness-raising" are not specifically aimed at these kinds of habitats ${ }^{8}$.

Less intuitively, we can also see that "Regulatory strengthening" types of measure are less favoured for both $\mathrm{CTH}$ and "Freshwater habitats", compared to other kinds of habitats. We can assume that this is due to the availability of two other kinds of direct interventions (6 and 9).

\footnotetext{
${ }^{8}$ Of course, these results are dependent on the level of aggregation of our categories. We can for example suppose that coastal terrestrial habitats are in fact more specifically concerned by a sub-category of "Communication/awareness-raising" instruments such as information signage.
} 
For Coastal Marine Habitats $(\mathrm{CMH})$, we observe that three kinds of instruments are statistically prioritised: "3. Institutional outsourcing”, “7. Regulatory strengthening”, "2. N2K project steering" and "4. Communication/awareness-raising".

The "Institutional outsourcing" category refers most of the time to future decisions and actions on the part of other institutional frameworks. These frameworks include land acquisition programs, management plans of other protected or managed areas (e.g. marshlands, sites of the National Coastal and Lake shore Conservation Authority...), urban planning documents, water policy documents, and all the different programs stemming from exogenous policies. It may be considered the poorest conservation measure for $\mathrm{N} 2 \mathrm{~K}$ since it would mean that all conservation actions will be implemented by the existing policy framework. On the other hand, it may be considered as a good way to have an integrative approach of various environmental policies at a specific territorial scale.

In contrast to the previous category, "Regulatory strengthening" actions make an explicit reference to a regulatory approach, in terms of reinforcement or enforcement. As such, they can be seen as a more "advanced" and precise version of some "Institutional outsourcing" approaches. They can advocate, among other things, extension of the site $^{9}$, creation of new protected areas with a stronger regulatory power, restrictions imposed on a specific activity by municipal bylaw, or the reference to the "réglement" of a SAGE ${ }^{10}$. Measures 3 and 7 are conceptually close to one another in the sense that they both make reference to exogenous (with respect to $\mathrm{N} 2 \mathrm{~K}$ ) institutional frameworks.

They are completed by two modes of action, based on the activity of the project manager (2), and on different means of communicating to end users (4).

Contrarily to CTH, CMH don't seem to statistically encourage "Physical regulation of access", even though delineating "forbidden areas" by means of buoys has been proposed in some sites. This may be partly due to technical issues: physically restricting access to some areas is difficult because fencing or barriers are not easy to install on water. We can also see that "Ecological engineering" (9.) is not favoured either for CMH. This may be due to problems of accessibility and lack of knowledge,

\footnotetext{
${ }^{9}$ This is considered as "strengthening" because more activities are in this way concerned by the Natura 2000 impact assessment requirements.

${ }^{10}$ In France, the water policy is based on framework planning documents for watersheds (SDAGE), local (SAGE) versions of which are produced for sub-watersheds. Since 2006, these documents must include a "regulatory part" (L212-5-1 Environmental Code).
} 
but also to the administrative restrictions on using contracts in marine areas, and to the costs of underwater ecological engineering. We have noted that artificial reefs have been proposed in some cases (e.g. (Licari et al., 2006, pp. 39-43)), but this seems to be an exception rather than the rule.

Interestingly, "Data production" (1.) doesn't seem to be particularly associated with CMH. This is quite counterintuitive given that marine habitats, because of their poor accessibility, may have been the subject of fewer previous studies, and that more globally, the lack of knowledge was considered as a limitation for the extension of the Natura 2000 network to the sea (European Commission, 2007). Knowledge actions could also have been a fallback measure for marine habitats, but our data don't seem to support this hypothesis.

As one would expect, "8. Financial incentive" is associated with "terrestrial non-forest" habitats, due to the possibility of offering measures built around agri-environmental contracts. But interestingly, contracts (which are also possible with forest owners) don't seem to be specifically proposed for forest habitats. More generally, our data show that there is no statistical trend of favouring specific types of measure for these forest habitats.

\section{Discussion}

The results of subsection 3.1 suggest that, in terms of levels of the measures (see left-hand side of Figure 5), the N2K Docobs are not - for the time being, in any case - aimed in practical terms at modifying existing practices and behaviours. The most cited use-oriented type of measure (category 4 : communication) can also be considered as the least binding one. We could tender the hypothesis that this trend is the direct outcome of a complicated deployment history for $\mathrm{N} 2 \mathrm{~K}$ that largely determined subsequent choices with regard to administrative tools and "policy-marketing" towards local stakeholders. In short, the local choice of non-binding instruments is consistent with the non-binding institutional context of Natura 2000 in France. The content of the Docobs might then illustrate the trade-off - driven by social acceptance considerations - between surface areas covered by the network and the normativity of the conservation measures adopted in these areas. This has been suggested in a broader context for Marine Protected Areas (Féral, 2011). 
Emphasizing the free commitment of stakeholders does not exclude, in principle, attempts to change practices: this is the underlying idea of financial incentive. However, our analysis tends to show that even the "N2K contracts" are seen more as a funding stream for restoration actions or facility installation (in the spirit of subsidies, for instance to install fences) rather than a compensation for changing an impacting practice. In brief, so far, $\mathrm{N} 2 \mathrm{~K}$ contracts seem to be mainly aimed at "enabling environmental stakeholders to do more" rather than "encouraging economic stakeholders to do differently". This idea is confirmed by the apparent relative failure of the N2K charter, i.e. a commitment to "do differently" without financial compensation ${ }^{11}$.

Nevertheless, our results show that the logic of more coercive interventions (through measure 6, and above all measure 7) is not totally excluded. Our models give first answers on the factors influencing the emergence of these less commonly adopted approaches.

The fact that targeting Coastal terrestrial habitats is associated with "Physical regulation of access", and "Ecological engineering", is consistent with what can be observed elsewhere in Europe in relation to coastal dune management (see the prevalence of "Physical measures" in (Kindermann and Gormally, 2013 Table 1)). This is also consistent with recent management recommendations based on biological conservtion actions (Ciccarelli, 2014; Kerbiriou et al., 2008).

The general picture of the Docob content makes the orientation of marine areas towards the less promoted types of measure, all the more noticeable. It is interesting to note that the management of coastal marine habitats appears to be geared to working in two different directions simultaneously: on the one hand, an outsourced, and more State-driven, approach (measures 3/7) takes programmes in one direction, while on the other hand, an approach based on stakeholders' interactions and nonbinding incentives (measures 2/4) takes them in another. Measure 3 is not State-driven by essence. But our analysis reveals that it is positively linked with measure 7 (see Table 3). Applying a causal interpretation, "Institutional outsourcing" is often promoted as a means of implementing "Regulatory strengthening" intervention.

\footnotetext{
${ }^{11}$ Signing an N2K charter is actually compensated by a tax exemption, but according to different stakeholders, the amount of this exemption wouldn't justify the commitment. This question deserves closer examination, which would require access to very disseminated tax data.
} 
This orientation towards State-driven approaches may be partly due to the public character of marine areas, giving more political legitimacy to the State action. But this may also come from the special link that exists between marine ecosystems and marine usages. As suggested by Ostermann (1998) many terrestrial habitats depend on extensive agricultural practices. Thus, a biodiversity policy will try to orientate practices towards an "optimum", somewhere between abandonment and intensive agriculture. Conversely, while marine habitats are not, generally, positively shaped by usages but only impacted in negative ways (to varying degrees), then it seems logical to favour more regulatory perspectives to "lift" human pressures (Morris et al., 2014, p. 41).

Our hypothesis is that the second direction of action (measures 2/4) shall be seen as complementary (and not opposed) to the first one (measures 3/7). Indeed, policies reflecting more regulatory actions in marine areas are likely to give rise to misunderstandings or protests based on marine/terrestrial equity considerations, unless additional efforts are made in communication (measure 4) and enhancement of collective governance (measure 2).

The promotion of measures 3/7 suggests that the French contractual/conventional framework for N2K seems to fall short of solutions with respect to marine areas. Put differently, N2K actions and results on the marine environment may be more dependent on the support of exogenous institutional frameworks. As Docobs are non-binding documents, this support is only hypothetical. Then a large part of the implementation is expected to depend on the ability of local $\mathrm{N} 2 \mathrm{~K}$ project managers to interact with exogenous frameworks and ensure the integration of $\mathrm{N} 2 \mathrm{~K}$ objectives into those frameworks.

The strategy of "institutional outsourcing" is echoed by the Marine Strategy Framework Directive 2008/56/EC (MSFD), in particular recitals 9 and articles 1(4) fostering the "integration of environmental concerns into other policies" (European Parliament and Council of the European Union, 2008, recital 9). However, it is noteworthy that the MSFD presents the N2K network as a means of reaching its own general environmental objectives (see recitals 6 and 18, article 13(4)). This presentation of $\mathrm{N} 2 \mathrm{~K}$ as a "tool" obscures the fact that some external integration objectives (reflecting internal institutional limits) have already been promoted within the network, and should now be 
effectively taken into account by other policies to allow them to bear fruits. This signals the need for clarification about which policy will, finally, effect change in favour of the marine environment.

The creation in 2006 in France of a new State institution, the Marine Protected Area Agency, is symbolically consistent with the State-driven trend highlighted above. This agency is in charge of implementing the strategy for creating Marine Protected Areas (MPA), including marine parts of Natura 2000 sites. However, it is still unclear how an agency, intrinsically devoted to MPA deployment, can resolve the issue of N2K integration within other policies (measure 3). Besides, the management of N2K sites is expected to be ensured by local "antennas" (or branches) of the Agency, in a rather more "centralized" way than for terrestrial sites, and probably with less human resources. Indeed, there may be some "budgetary competition" between the different MPAs, and in particular between N2K sites and the increasing number of Marine Nature Parks ${ }^{12}$. Our data show that this institutional evolution may not fit with the "interactive" orientation (measures $2 / 4$ ) suggested by the Docobs for N2K marine areas.

On the same issue of human and material resources, it is important to highlight that "Regulatory strengthening" actions often ${ }^{13}$ refer to the enforcement of existing laws and regulations, by a strengthening of policing effort or administrative controls for different activities (fishing, plant picking, agriculture, driving within natural areas etc). This suggests that, even if the lack of regulatory scope can be seen as a limitation for a Natura 2000 site, the question of enforcement of existing (and $a$ fortiori future) regulations, and in particular of the necessary corresponding knowledge and human and material resources, may be the "final hurdle". This may be all the more true for marine areas, where physical regulation of access and ecological engineering don't seem to be readily available options, in contrast to coastal terrestrial habitats.

\section{Methodological limits and prospects}

\footnotetext{
${ }^{12}$ This is an ongoing process: between 28 September 2007 and 1 November 2016, 8 Marine Nature Parks have been created. 2 additional "feasibility missions" are still working.

${ }^{13}$ Of the 1378 actions studied, 102 promote "Regulatory strengthening". Of these 102 actions, 44 refer to "Outdoor (police) monitoring" for law enforcement. 21 other actions refer to already existing obligations and protection, 10 to general enforcement consideration, and 11 to a modification/strengthening of these obligations.
} 
Our quantitative work exhibits several limitations, partly because it is based on material that is, for the most part, qualitative: the Docob. The form this material takes is very heterogeneous, which raises the question of "intrinsic" comparability of the individual statistical units (the action-sheets). As mentioned previously, we withdrew some Docobs that were not deemed comparable to others, but this choice is subjective to a certain extent. We consider there is no obvious technical solution to this problem, and we hope that the future generations of management plans, thanks to best practice sharing and template diffusion, will be more similar to one another. More homogeneity would then allow coding of more actions (reduction of processing time), or exploitation of other aspects of the Docobs (bibliography, institutional context, analysis of local usages and their impacts, details of biodiversity data, follow-up indicators, etc). In the current context, our experience leads us to think that such detailed explorations can only be carried out for a reduced number of case studies, and thus with a lesser degree of comparability and generality. If one wanted to go further in quantitative analyses, we think that a good strategy would be to focus on specific measures, and to adapt the sampling strategy (based, for instance, on the frequencies that we determined for the different measures). Although the scope of such an approach would be less general, it would lessen the problem of the questionable use of typologies and generic labels to over-simplify very heterogeneous realities.

In addition to this problem of subjectivity regarding what a "conservation measure" (and the corresponding action-sheet) is, the notion of "type of measure" is also subjective. The writer of a Docob does not necessarily adopt the same conventions as an analyst to describe the measures. Consequently, some of them were difficult to classify because of the lack of precision of the actionsheet (with respect to our conventions). In particular, there seemed to be a frequent confusion or combination between two types of measure we decided to separate into two distinct ones: a financial compensation for opportunity costs linked to a change in an impacting practice (the spirit of our category "8. Financial incentive") ${ }^{14}$ and a financial compensation for production cost for a delivered environmental service, closely resembling environmental engineering (the spirit of our category "9. Ecological/civil engineering"). Globally, N2K contracts seem to be mainly used for the latter. Similar difficulties of classification arose between categories 1 and 2 (data production/follow-up), 2 and 4

\footnotetext{
${ }^{14}$ Other forms of financial incentive (e.g. access fee) were rarely suggested.
} 
(general management of information/communication towards specific users), or 3 and 7 (institutional outsourcing without regulation/promotion of regulatory schemes exogenous to $\mathrm{N} 2 \mathrm{~K}$ ), as suggested by the correlation between these categories (see Table 3).

Another limitation of this work is that whether some policy scheme is considered as an instrument or not is partly dependent on the level of analysis adopted and/or on the step of the policy process concerned. For instance, from a global perspective of the Natura 2000 program, public participation in the planning process (in drafting the Docob), could be seen as an instrument (for solving conflicts, raising environmental awareness...) (Pinton et al., 2006, p. 91). But from the perspective of the measures written in the Docob, this participation is largely a "past" process, and is seldom presented as an instrument of future action. Besides, the Natura 2000 impact assessment (HD, article 6(3)) is essentially an administrative process which takes place quite independently of the implementation of the Docobs. As such, it is seldom mentioned by the Docobs as an instrument within their "jurisdiction".

\section{Conclusion}

Based on the case of French Natura 2000 coastal sites, this research is among the first attempts to study quantitatively the "conservation measures" proposed to manage the Natura 2000 network, and to explore the local determinants of the choice of different types of measure (or, put differently, of different policy instruments). We show a clear specificity of the measures proposed for coastal habitats with respect to "terrestrial" ones. In particular, these results raise some doubt about the ability of the marine part of the network to contribute in an autonomous way to an improvement of the state of biodiversity.

However, Docobs are snapshots of moments in time, with a long exposure, of the life of a N2K site, and of management intentions of local stakeholders. A large-scale exploration of the Docob implementation phase is now essential to complete our analysis with more practical considerations. Such work would need to be carried out covering many other issues related to political, demographical and socio-economic variables. Ideally, this analysis would embrace the broader national scale, to 
complete our coverage of all $\mathrm{N} 2 \mathrm{~K}$ sites, and so improve the representativeness of our case studies sample.

\section{Acknowledgments:}

The authors would like to thank the French Ministry of the Environment, Energy and the Sea, and the French Research Institute for Exploitation of the Sea (Ifremer) for their financial, material and technical support throughout the project. The views expressed in the article are those of the authors and in no way reflect the positions of these institutions.

Special thanks go to Philippa Bush and the two anonymous reviewers for their sound comments.

\section{References}

AAMP, 2012. Boîte à outils Natura 2000. Inventaire des mesures de gestion des espèces et habitats marins Natura 2000 en Manche-Mer du Nord (Document de travail). Agence des Aires Marines Protégées - Sous-région marine manche-Mer du Nord.

Adger, W.N., Brown, K., Fairbrass, J., Jordan, A., Paavola, J., Rosendo, S., Seyfang, G., 2003. Governance for sustainability: towards a "thick" analysis of environmental decisionmaking. Environ. Plan. A 35, 1095 - 1110. doi:10.1068/a35289

Aho, K., Derryberry, D., Peterson, T., 2014. Model selection for ecologists: the worldviews of AIC and BIC. Ecology 95, 631-636. doi:10.1890/13-1452.1

Alphandéry, P., Fortier, A., 2010. Local Settings and Biodiversity: A Sociological Approach to the Implementation of the EC Habitats Directive in France. Curr. Sociol. 58, 755-776. doi:10.1177/0011392110372737

Alphandéry, P., Fortier, A., 2001. Can a Territorial Policy be Based on Science Alone? The System for Creating the Natura 2000 Network in France. Sociol. Rural. 41, 311-328.

Apostolopoulou, E., Drakou, E.G., Pediaditi, K., 2012. Participation in the management of Greek Natura 2000 sites: Evidence from a cross-level analysis. J. Environ. Manage. 113, 308-318. doi:10.1016/j.jenvman.2012.09.006

Apostolopoulou, E., Pantis, J.D., 2009. Conceptual gaps in the national strategy for the implementation of the European Natura 2000 conservation policy in Greece. Biol. Conserv. 142, 221-237. doi:10.1016/j.biocon.2008.10.021

Bemelmans-Videc, M.-L., Rist, R.C., Vedung, E., 1998. Carrots, Sticks and Sermons, Marie-Louise Bemelmans-Videc, Ray C. Rist, Evert Vedung. ed. Transaction Publishers, New Brunswick, New Jersey.

Beunen, R., de Vries, J.R., 2011. The governance of Natura 2000 sites: the importance of initial choices in the organisation of planning processes. J. Environ. Plan. Manag. 54, 1041-1059. doi:10.1080/09640568.2010.549034 
Beunen, R., Van Assche, K., Duineveld, M., 2013. Performing failure in conservation policy: The implementation of European Union directives in the Netherlands. Land Use Policy, Themed Issue 1-Guest Editor Romy GreinerThemed Issue 2- Guest Editor Davide Viaggi 31, 280-288. doi:10.1016/j.landusepol.2012.07.009

Beunen, R., van der Knaap, W.G.M., Biesbroek, G.R., 2009. Implementation and integration of EU environmental directives. Experiences from The Netherlands. Environ. Policy Gov. 19, 57-69. doi:10.1002/eet.495

Blicharska, M., Orlikowska, E.H., Roberge, J.-M., Grodzinska-Jurczak, M., 2016. Contribution of social science to large scale biodiversity conservation: A review of research about the Natura 2000 network. Biol. Conserv. 199, 110-122. doi:10.1016/j.biocon.2016.05.007

Borrass, L., 2014. Varying practices of implementing the Habitats Directive in German and British forests. For. Policy Econ. 38, 151-160. doi:10.1016/j.forpol.2013.05.008

Burnham, K.P., Anderson, D.R., 2014. P values are only an index to evidence: 20th- vs. 21st-century statistical science. Ecology 95, 627-630. doi:10.1890/13-1066.1

Burnham, K.P., Anderson, D.R., Huyvaert, K.P., 2011. AIC model selection and multimodel inference in behavioral ecology: some background, observations, and comparisons. Behav. Ecol. Sociobiol. 65, 23-35. doi:10.1007/s00265-010-1029-6

Calcagno, V., De Mazancourt, C., 2010. glmulti: An R Package for Easy Automated Model Selection with (Generalized) Linear Models. J. Stat. Softw. 34.

Cent, J., Mertens, C., Niedziałkowski, K., 2013. Roles and impacts of non-governmental organizations in Natura 2000 implementation in Hungary and Poland. Environ. Conserv. 40, 119-128. doi:10.1017/S0376892912000380

Ciccarelli, D., 2014. Mediterranean Coastal Sand Dune Vegetation: Influence of Natural and Anthropogenic Factors. Environ. Manage. 54, 194-204. doi:10.1007/s00267-014-0290-2

Cicin-Sain, B., Belfiore, S., 2005. Linking marine protected areas to integrated coastal and ocean management: A review of theory and practice. Ocean Coast. Manag., Integrated MPA Management with Coastal and Ocean Governance: Principles and Practices 48, 847-868. doi:10.1016/j.ocecoaman.2006.01.001

De Blust, G., Kruk, R.W., Van Apeldoorn, R.C., Sier, A., 2010. Information and communication on the designation and management of Natura2000 sites. Main Report 3: Towards Integrated Management (Publication - Report).

Dubois, J., 2005. Quels périmètres protéger? Les formes d'arbitrages territoriaux, in: Natura 2000. De L’injonction Européenne Aux Négociations Locales, Monde Européen et International. La Documentation française, Paris, pp. 107-128.

Ellison, A.M., Gotelli, N.J., Inouye, B.D., Strong, D.R., 2014. P values, hypothesis testing, and model selection: it's déjà vu all over again. Ecology 95, 609-610. doi:10.1890/13-1911.1

Environment Directorate-General, 2015a. Natura 2000 and Forests. Part III - Case studies (Technical report No. 2015-089). European Commission.

Environment Directorate-General, 2015b. Natura 2000 Barometer - Update 2014. Nat. 2000 Newsl. 16.

European Commission, 2007. Guidelines for the establishment of the Natura 2000 network in the marine environment . Application of the Habitats and Birds Directives. 
European Commission, Olmeda, C., 2014. Establishing conservation measures for Natura 2000 sites. European Commission.

European Parliament, Council of the European Union, 2008. Directive 2008/56/EC of the European Parliament and of the Council of 17 June 2008 establishing a framework for community action in the field of marine environmental policy (Marine Strategy Framework Directive), OJ L164/19.

European Union, 2012. Consolidated versions of the Treaty on European Union and the Treaty on the Functioning of the European Union. Off. J. Eur. Union 55. doi:doi:10.3000/1977091X.C_2012.326.eng

Féral, F., 2011. L'extension récente de la taille des aires marines protégées : une progression des surfaces inversement proportionnelle à leur normativité. VertigO - Rev. Électronique En Sci. Environ. doi:10.4000/vertigo.10998

Ferranti, F., Beunen, R., Speranza, M., 2010. Natura 2000 Network: A Comparison of the Italian and Dutch Implementation Experiences. J. Environ. Policy Plan. 12, 293-314. doi:10.1080/1523908X.2010.505417

Ferranti, F., Turnhout, E., Beunen, R., Behagel, J.H., 2014. Shifting nature conservation approaches in Natura 2000 and the implications for the roles of stakeholders. J. Environ. Plan. Manag. 57, 1642-1657. doi:10.1080/09640568.2013.827107

Garamszegi, L.Z., 2011. Information-theoretic approaches to statistical analysis in behavioural ecology: an introduction. Behav. Ecol. Sociobiol. 65, 1-11. doi:10.1007/s00265-010-1028-7

Garamszegi, L.Z., Calhim, S., Dochtermann, N., Hegyi, G., Hurd, P.L., Jørgensen, C., Kutsukake, N., Lajeunesse, M.J., Pollard, K.A., Schielzeth, H., Symonds, M.R.E., Nakagawa, S., 2009. Changing philosophies and tools for statistical inferences in behavioral ecology. Behav. Ecol. 20, 1363-1375. doi:10.1093/beheco/arp137

Grodzinska-Jurczak, M., Cent, J., 2011. Expansion of Nature Conservation Areas: Problems with Natura 2000 Implementation in Poland? Environ. Manage. 47, 11-27. doi:10.1007/s00267$010-9583-2$

Hegyi, G., Garamszegi, L.Z., 2011. Using information theory as a substitute for stepwise regression in ecology and behavior. Behav. Ecol. Sociobiol. 65, 69-76. doi:10.1007/s00265-010-1036-7

Hiedanpaa, J., Bromley, D.W., 2011. The Harmonization Game: Reasons and Rules in European Biodiversity Policy. Environ. Policy Gov. 21, 99-111. doi:10.1002/eet.561

Hood, C., 2007. Intellectual Obsolescence and Intellectual Makeovers: Reflections on the Tools of Government after Two Decades. Governance 20, 127-144. doi:10.1111/j.14680491.2007.00347.x

Hosmer, D.W., Lemeshow, S., Sturdivant, R.X., 2013. Applied logistic regression, 3rd ed, Wiley Series in Probability and Statistics. Wiley.

Kamal, S., Kocór, M., Grodzińska-Jurczak, M., 2015. Conservation opportunity in biodiversity conservation on regulated private lands: Factors influencing landowners' attitude. Environ. Sci. Policy 54, 287-296. doi:10.1016/j.envsci.2015.07.023

Kerbiriou, C., Leviol, I., Jiguet, F., Julliard, R., 2008. The impact of human frequentation on coastal vegetation in a biosphere reserve. J. Environ. Manage. 88, 715-728.

doi:10.1016/j.jenvman.2007.03.034 
Kindermann, G., Gormally, M.J., 2013. Stakeholder perceptions of recreational and management impacts on protected coastal dune systems: A comparison of three European countries. Land Use Policy, Themed Issue 1-Guest Editor Romy GreinerThemed Issue 2- Guest Editor Davide Viaggi 31, 472-485. doi:10.1016/j.landusepol.2012.08.011

Kruk, R.W., De Blust, G., Van Apeldoorn, R.C., Bouwma, I.M., Sier, A., 2010. Information and communication on the designation and management of Natura2000 sites. Main Report 2: Organizing the management in 27 EU Member States (Publication - Report).

Lascoumes, P., Le Galès, P., 2007. Introduction: Understanding Public Policy through Its Instruments _ From the nature of Instruments to the Sociology of Public Policy Instrumentation. Gov. Int. J. Policy Adm. Inst. 20, 1-21.

Licari, M.-L., Binche, J.-L., Laffon, J.-F., Cadene, F., Ferrari, B., 2006. Document d'objectifs site Natura 2000 «Posidonies de la Côte des Albères». Phase III : Propositions des mesures de gestion et de suivi. Conseil Général.

Link, W.A., Barker, R.J., 2006. Model weights and the foundations of multimodel inference. Ecology $87,2626-2635$.

Lukacs, P.M., Burnham, K.P., Anderson, D.R., 2010. Model selection bias and Freedman's paradox. Ann. Inst. Stat. Math. 62, 117-125. doi:10.1007/s10463-009-0234-4

Menard, S., 2001. Applied Logistic Regression Analysis, 2nd edition. ed. SAGE Publications, Inc, Thousand Oaks, Calif.

Morris, R.K.A., Bennett, T., Blyth-Skyrme, R., Barham, P.J., Ball, A., 2014. Managing Natura 2000 in the marine environment - An evaluation of the effectiveness of "management schemes" in England. Ocean Coast. Manag. 87, 40-51. doi:10.1016/j.ocecoaman.2013.10.017

Mundry, R., Nunn, C.L., 2009. Stepwise Model Fitting and Statistical Inference: Turning Noise into Signal Pollution. Am. Nat. 173, 119-123. doi:10.1086/593303

Murtaugh, P.A., 2014. In defense of P values. Ecology 95, 611-617. doi:10.1890/13-0590.1

Murtaugh, P.A., 2009. Performance of several variable-selection methods applied to real ecological data. Ecol. Lett. 12, 1061-1068. doi:10.1111/j.1461-0248.2009.01361.x

Ostermann, O.P., 1998. The need for management of nature conservation sites designated under Natura 2000. J. Appl. Ecol. 35, 968-973. doi:10.1111/j.1365-2664.1998.tb00016.x

Paloniemi, R., Apostolopoulou, E., Cent, J., Bormpoudakis, D., Scott, A., Grodzińska-Jurczak, M., Tzanopoulos, J., Koivulehto, M., Pietrzyk-Kaszyńska, A., Pantis, J.D., 2015. Public Participation and Environmental Justice in Biodiversity Governance in Finland, Greece, Poland and the UK. Environ. Policy Gov. n/a-n/a. doi:10.1002/eet.1672

Perret, S., 2010. Vers une nouvelle approche instrumentale des politiques publiques de protection de l'environnement : implications conceptuelles, théoriques et méthodologiques à la lumière du cas de la politique climatique suisse. University of Geneva.

Pinton, F., Alphandéry, P., Billaud, J.-P., Deverre, C., Fortier, A., Géniaux, G., 2006. La construction du réseau Natura 2000 en France, L'environnement en question. La Documentation française, Paris.

Popescu, V.D., Rozylowicz, L., Niculae, I.M., Cucu, A.L., Hartel, T., 2014. Species, Habitats, Society: An Evaluation of Research Supporting EU's Natura 2000 Network. PLoS ONE 9, e113648. doi:10.1371/journal.pone.0113648 
Posada, D., Buckley, T.R., 2004. Model Selection and Model Averaging in Phylogenetics: Advantages of Akaike Information Criterion and Bayesian Approaches over Likelihood Ratio Tests. Syst. Biol. 53, 793-808.

Rakotomalala, R., 2014. Pratique de la Régression Logistique. Régression Logistique Binaire et Polytomique. Version 2.0 (Polycopié de cours). Université Lumière Lyon 2.

R Core Team, 2013. R: A language and environment for statistical computing. R Foundation for Statistical Computing. Vienna, Austria.

Sadeleer, N. de, Milieu Ltd., 2009. National legislation and practices regarding the implementation of Council Directive 92/43/EEC of 21 May 1992 on the conservation of natural habitats and of wild fauna and flora, in particular Article 6 (No. PE 410.98). European Parliament, Petitions Committee.

Sanharawi, M. El, Naudet, F., 2013. Comprendre la régression logistique. J. Fr. Ophtalmol. 36, 710715. doi:10.1016/j.jfo.2013.05.008

Santos, G., Maoh, H., Potoglou, D., von Brunn, T., 2013. Factors influencing modal split of commuting journeys in medium-size European cities. J. Transp. Geogr. 30, 127-137. doi:10.1016/j.jtrangeo.2013.04.005

Souheil, H., Germain, L., Boivin, D., Douillet, R., 2011. Guide méthodologique d'élaboration des Documents d'objectifs Natura 2000 (Cahier technique No. 82), Outils de gestion et de planification. Atelier Technique des Espaces Naturels, Montpellier.

Stancioiu, P. t., Abrudan, I. v., Dutca, I., 2010. The Natura 2000 Ecological Network and Forests in Romania: Implications on Management and Administration. Int. For. Rev. 12, 106-113. doi:10.1505/ifor.12.1.106

Symonds, M.R.E., Moussalli, A., 2011. A brief guide to model selection, multimodel inference and model averaging in behavioural ecology using Akaike's information criterion. Behav. Ecol. Sociobiol. 65, 13-21. doi:10.1007/s00265-010-1037-6

Tsianou, M.A., Mazaris, A.D., Kallimanis, A.S., Deligioridi, P.-S.K., Apostolopoulou, E., Pantis, J.D., 2013. Identifying the criteria underlying the political decision for the prioritization of the Greek Natura 2000 conservation network. Biol. Conserv. 166, 103-110. doi:10.1016/j.biocon.2013.06.021

Van Apeldoorn, R.C., Kruk, R.W., Bouwma, I.M., Ferranti, F., De Blust, G., Sier, A., 2010. Information and communication on the designation and management of Natura2000 sites. Summary Main Report 1: The designation in 27 EU Member States (Publication - Report).

Vedung, E., 1998. Policy Instruments: Typologies and Theories, in: Carrots, Sticks and Sermons. Transaction Publishers, New Brunswick, New Jersey, pp. 21-58.

Verschuuren, J.M., 2002. Implementation of the Convention on Biodiversity in Europe: 10 Years of Experience with the Habitats Directive. J. Int. Wildl. Law Policy 5, 251-267.

Welch-Devine, M., 2011. Implementation and Resistance: Networking to Create and Renegotiate Natura 2000. J. Nat. Resour. Policy Res. 3, 287-302. doi:10.1080/19390459.2011.591756

Whittingham, M.J., Stephens, P.A., Bradbury, R.B., Freckleton, R.P., 2006. Why do we still use stepwise modelling in ecology and behaviour? J. Anim. Ecol. 75, 1182-1189.

doi:10.1111/j.1365-2656.2006.01141.x

Winkel, G., Blondet, M., Borrass, L., Frei, T., Geitzenauer, M., Gruppe, A., Jump, A., de Koning, J., Sotirov, M., Weiss, G., Winter, S., Turnhout, E., 2015. The implementation of Natura 2000 in 
forests: A trans- and interdisciplinary assessment of challenges and choices. Environ. Sci. Policy 52, 23-32. doi:10.1016/j.envsci.2015.04.018

Winter, S., Borrass, L., Geitzenauer, M., Blondet, M., Breibeck, R., Weiss, G., Winkel, G., 2014. The impact of Natura 2000 on forest management: a socio-ecological analysis in the continental region of the European Union. Biodivers. Conserv. 23, 3451-3482. doi:10.1007/s10531-014$0822-3$

Young, J.C., Jordan, A., R. Searle, K., Butler, A., S. Chapman, D., Simmons, P., Watt, A.D., 2013. Does stakeholder involvement really benefit biodiversity conservation? Biol. Conserv. 158, 359-370. doi:10.1016/j.biocon.2012.08.018 


\section{SUPPLEMENTARY MATERIAL}

\section{Appendix A : Detailed typology of the types of measure}

In our database, each type of measure was identified by a code in the format "M20" + number of the type of measure. For instance, M204 corresponded to "4. Communication/awareness-raising". These codes are indicated at the tope left-hand corner of the tables below.

\begin{tabular}{|l|l|l|}
\hline M201 & \multicolumn{1}{|c|}{ 1. Data production } & \\
\hline $\begin{array}{l}\text { Measures aimed at producing information (about usages, about the environment, or about the link } \\
\text { between pressure on, and the state of, the environment), before actual measures are implemented. }\end{array}$ \\
\hline$\underline{\underline{\text { Included }}}$ & $\begin{array}{l}\text { Measures appealing external expert organizations (e.g. universities, } \\
\text { laboratories...), or more specifically aimed at developing scientific } \\
\text { collaborations or ecological experimentations. }\end{array}$ & $\begin{array}{l}\text { Excluded } \\
\text { Measures of monitoring of other operational measures (explicitly } \\
\text { conditional on the implementation of other measures like ecological } \\
\text { engineering) } \\
\text { Measures of knowledge dissemination }\end{array}$ \\
\hline$\underline{\text { Associated level of action }}$ & Knowledge & $\rightarrow \mathrm{M} 202$ \\
\end{tabular}

\begin{tabular}{|l|l|l|}
\hline M202 & \multicolumn{1}{|c|}{ 2. N2K Project steering } & - \\
\hline $\begin{array}{l}\text { General steering measures aimed at accompanying the N2K process: meetings of the Copil and } \\
\text { subsequent collective decisions, maintenance of facilities, specifications and follow-up of other } \\
\text { measures, database management, general dissemination of knowledge. }\end{array}$ \\
$\begin{array}{l}\text { Primarily used in the absence of a more precise description of one of the other types a given measure } \\
\text { deployed. }\end{array}$ \\
\hline$\underline{\text { Included }}$ & $\begin{array}{l}\text { Participatory approaches stemming from N2K } \\
\text { Communication/awareness-raising for the general public (e.g. experience } \\
\text { sharing in schools, website maintenance...) }\end{array}$ & $\rightarrow \mathrm{M} 204$ \\
\hline Excluded & Communication towards definite users & \\
\hline Associated level of action & Governance &
\end{tabular}

\section{\begin{tabular}{l|l} 
M203 & 3. Institutional outsourcing
\end{tabular}}

An external institution/organization will be in charge of the conservation action with regards to other existing public policies, with no explicit regulatory dimension (e.g. Water policy planning documents, urban planning documents, management plans of other protected areas...).

Included Support and communication with the State services, local institution services or other kind of public services.

Actions aimed at supporting the N2K Impact Assessment within the site.

Excluded Communication towards specific users (out of collective organizations). Measures with a more specific objective, like implementing a charter/contract linked with $\mathrm{N} 2 \mathrm{~K}$, or a specific regulation (e.g. explicit mention of a regulation through a planning document)

\section{\begin{tabular}{l|l} 
Associated level of action & Governance \\
\hline
\end{tabular}}

\begin{tabular}{|l|l|}
\hline M204 & 4. Communication/awareness-raising \\
\hline
\end{tabular}

Communication measures aimed at specific user groups having an impact on the environment, via a range of media (signs, posters, fliers, direct communication...).

\begin{tabular}{l|l}
\hline Included & Communication about an already existing regulation
\end{tabular} 
\begin{tabular}{l|l} 
Associated level of action & Practices and behaviours \\
\hline
\end{tabular}

\begin{tabular}{|l|l|l|}
\hline M205 & \multicolumn{1}{|c|}{ 5. Charter/code of conduct } & \\
\hline $\begin{array}{l}\text { Measures aimed at modifying the behaviour of users through a charter, code of conduct, code of } \\
\text { practice, management specification for eco-labelling. }\end{array}$ \\
\hline$\underline{\underline{\text { Included }}}$ & $\begin{array}{l}\text { Natura 2000 Charter } \\
\text { Support to labelling approaches }\end{array}$ \\
\hline$\underline{\text { Excluded }}$ & $\begin{array}{l}\text { External conventions linked to the management of natural areas, under } \\
\text { the form of contracts with individuals }\end{array}$ & $\rightarrow \mathrm{M} 208$ \\
\hline$\underline{\text { Associated level of action }}$ & Practices and behaviours
\end{tabular}

\begin{tabular}{|c|c|c|}
\hline \multirow{2}{*}{\multicolumn{3}{|c|}{\begin{tabular}{l|c|c} 
M206 & 6. Physical regulation of access & \\
Measures of "physical" incentive, such as fencing, beacons, markers, channelling infrastructures... \\
Users generally remain free to follow the incentive or not.
\end{tabular}}} \\
\hline & & \\
\hline Included & & \\
\hline Excluded & $\begin{array}{l}\text { Water management facilities (action on a semi-natural environment) } \\
\text { Technological solutions for impact mitigation (e.g. eco-facilities on road } \\
\text { or bridges) }\end{array}$ & $\rightarrow$ M209 \\
\hline
\end{tabular}

The «physical incentive » power of marine beaconing is questionable. The latter could be identified to a communication measure (sign).

\begin{tabular}{|l|ll|}
\hline M207 & 7. Regulatory strengthening & \\
\hline $\begin{array}{l}\text { Measures aimed at creating or enforcing a regulatory scheme (based on the underlying idea that the } \\
\text { State must define, or has defined, compulsory rules). This includes policing of environmental } \\
\text { regulations. }\end{array}$ & $\begin{array}{l}\text { Included } \\
\text { On-ground surveillance for an already existing regulatory scheme } \\
\text { External institutional approaches of which the regulatory dimension is } \\
\text { explicitly mentioned }\end{array}$ & $\rightarrow$ M203 \\
\hline Excluded & $\begin{array}{l}\text { Planning documents, management documents of other protected areas } \\
\text { (with no mention of specific regulation) } \\
\text { Communication on already existing regulations } \\
\text { On-ground facilities aimed at enforcing a regulation }\end{array}$ & $\rightarrow \mathrm{M} 204$ \\
\hline
\end{tabular}

\begin{tabular}{|l|l|l|}
\hline M208 & 8. Financial incentive & \\
\hline $\begin{array}{l}\text { Measures aimed at modifying existing practices through a contractual agreement or financial } \\
\text { instrument. Users remain free to follow the incentive or not. }\end{array}$ \\
$\begin{array}{l}\text { In case of uncertainty about the priori existence of the targeted practice, measures will generally be } \\
\text { listed as "Financial incentive" combined with "Ecological engineering" (payment for environmental } \\
\text { service). }\end{array}$ \\
\hline$\underline{\underline{\text { Included }}}$ & $\begin{array}{l}\text { Excluded } \\
\text { Measures using explicitly contracts as a funding mode or payment for } \\
\text { environmental service (e.g. mechanical control of invasive species) } \\
\text { Work of specification of contracts, promotion of contracts to potential } \\
\text { contracting parties, follow-up measures }\end{array}$ & $\rightarrow \mathrm{M} 209$ \\
\hline
\end{tabular}

\section{\begin{tabular}{|l|l|}
\hline M209 & 9. Civil/ecological engineering \\
\hline
\end{tabular}}

Measures aimed at creating facilities or setting up practices (typically one-off, but they could also be regularly implemented), which did not exist before, and are specifically designed to positively modify 


\begin{tabular}{|l|l|}
\hline the state of the natural environment, or technically mitigate an impact. \\
\hline$\underline{\text { Excluded }}$ & $\begin{array}{l}\text { Land clearance by mechanical methods or grazing } \\
\text { Technological solutions for impact mitigation (e.g. eco-facilities on road } \\
\text { or bridges, eco-anchorages) }\end{array}$ \\
\hline$\underline{\text { Associated level of action }}$ & State of the environment \\
\hline
\end{tabular}




\section{Appendix B : Details of explanatory variables related to habitats}

\section{$\underline{\text { Table B1 : Detail of habitat variables }}$}

Actions can target (and they often do) several kinds of habitats and species at the same time.

\begin{tabular}{|c|c|c|c|}
\hline$\underline{\text { Variable }}$ & $\underline{\text { Definition }}$ & $\underline{\text { Unit }}$ & $\underline{\text { Source }}$ \\
\hline HAB_Coastal.marine & $\begin{array}{l}\text { Does the action target at least one coastal marine } \\
\text { habitat? }\end{array}$ & $0=\mathrm{No} / 1=\mathrm{Yes}$ & $\begin{array}{c}\text { Coding + } \\
\text { Appendix B, } \\
\text { Table B2 }\end{array}$ \\
\hline HAB_Coastal.terrestrial & $\begin{array}{l}\text { Does the action target at least one coastal terrestrial } \\
\text { habitat? }\end{array}$ & $0=\mathrm{No} / 1=\mathrm{Yes}$ & $\begin{array}{c}\text { Coding + } \\
\text { Appendix B, } \\
\text { Table B2 }\end{array}$ \\
\hline HAB_Freshwater & Does the action target at least one freshwater habitat? & $0=\mathrm{No} / 1=\mathrm{Yes}$ & $\begin{array}{c}\text { Coding + } \\
\text { Appendix B, } \\
\text { Table B2 }\end{array}$ \\
\hline HAB_TerrestrialnForest & $\begin{array}{l}\text { Does the action target at least one terrestrial non forest } \\
\text { habitat? }\end{array}$ & $0=\mathrm{No} / 1=\mathrm{Yes}$ & $\begin{array}{c}\text { Coding + } \\
\text { Appendix B, } \\
\text { Table B2 }\end{array}$ \\
\hline HAB_Forest & Does the action target at least one forest habitat? & $0=\mathrm{No} / 1=\mathrm{Yes}$ & $\begin{array}{c}\text { Coding + } \\
\text { Appendix B, } \\
\text { Table B2 }\end{array}$ \\
\hline
\end{tabular}

The detailed association between Natura 2000 habitat codes and our 5-category typology is available upon request. 


\section{Appendix C : Number of Docobs versus year}

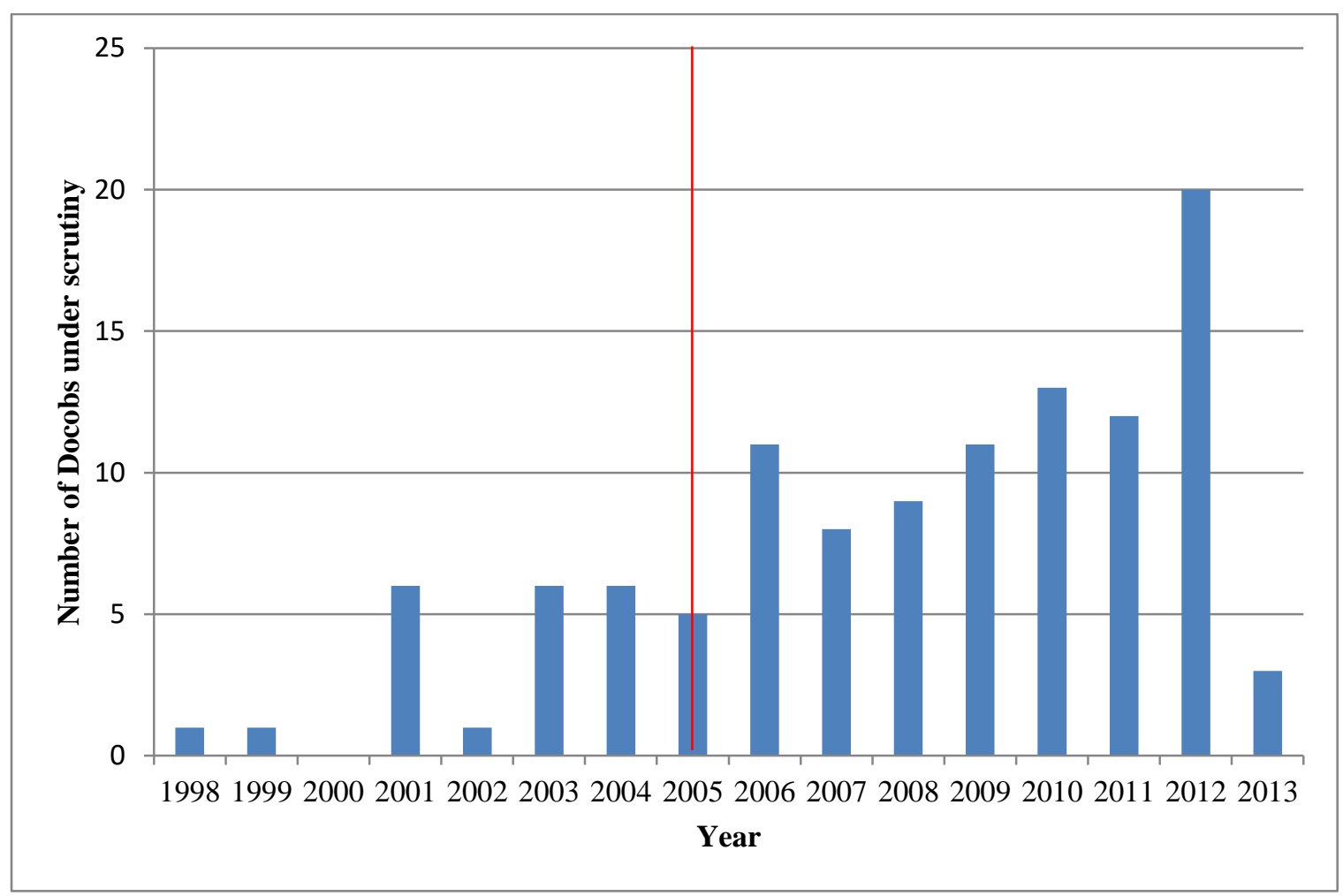

The red vertical line indicates the year of the law ${ }^{\circ} 2005-157$ creating the N2K Charter. 


\section{Appendix : Methodological details on the building of the models}

\section{Content}

Appendix : Methodological details on the building of the models

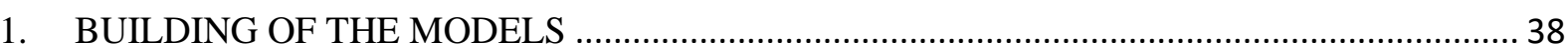

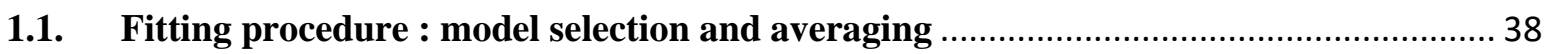

1.2. Number of Events Per independent Variable (EPV) : ................................................ 39

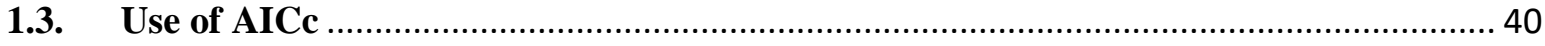

1.4. Multicollinearity : Variance Inflation Factor .............................................................. 40

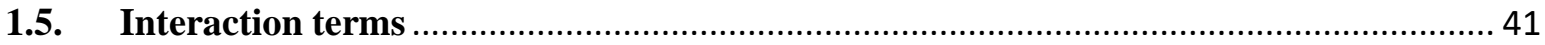

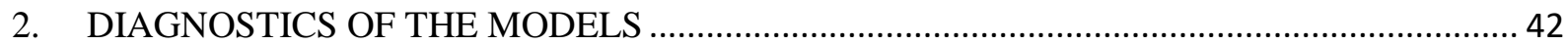

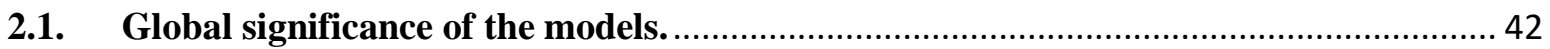

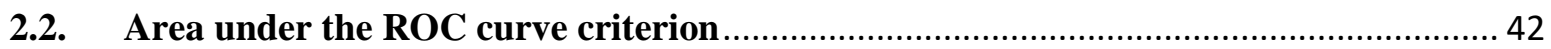

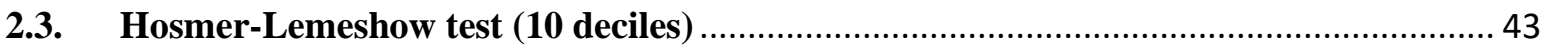

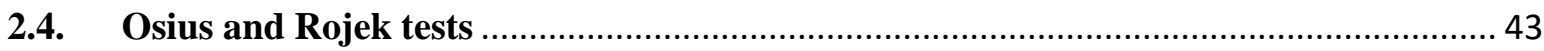

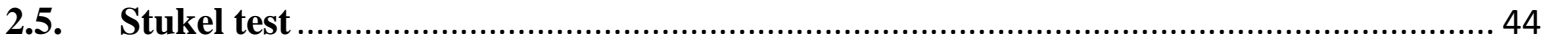

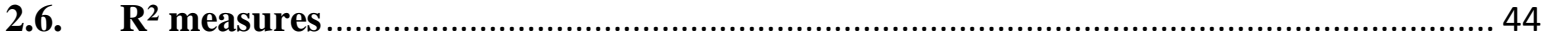

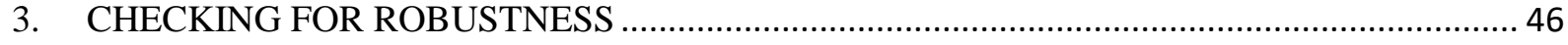

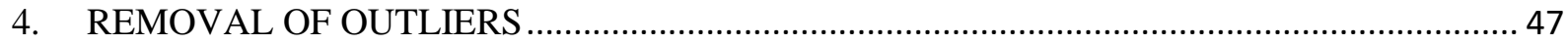

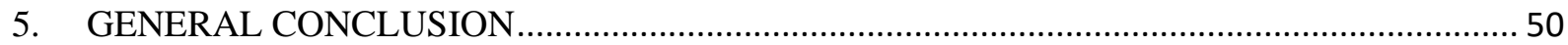

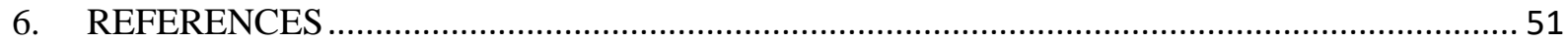

\section{BUILDING OF THE MODELS}

\subsection{Fitting procedure : model selection and averaging}

Key references : (Burnham et al., 2011; Burnham and Anderson, 2002; Garamszegi, 2011; Symonds and Moussalli, 2011)

Key points : there is uncertainty on the selection of an explanatory model (i.e. choice of relevant variables) in particular in exploratory approaches such as ours, and this uncertainty is not reflected when one presents a single final model.

$\rightarrow$ We use an model selection and averaging methodology based on the Akaike Information Criterion

$\rightarrow$ This method allows comparison of multiple non-nested models 
$\rightarrow$ We consider this approach to be the best trade-off between sound theory and easiness to compute (Posada and Buckley, 2004)

\section{Details}

"glmulti" (Calcagno and De Mazancourt, 2010) is a genetic algorithm which will explore semirandomly the explanatory models (i.e. combinations of variables) that can be built on a list of potential candidates variables. The criterion of selection is the minimization of the Akaike Inormation Criterion (AIC).

Once the algorithm has converged (basically, when the AIC cannot be noticeably reduced anymore), and "the 100 best models" 15 identified among all those explored, averaged values of coefficients and uncertainties linked to the model selection process can be computed, taking into account the weight wi of each model.

For a given variable, the sum of the Akaike weights of the models in which it appears gives the probability for the variable to be included in the best model in the sense of AIC, given the data and the $\mathrm{R}$ models considered. This sum of weights corresponds to the "Importance" computed by glmulti for each variable.

On top of this Importance, glmulti provides, for each variable, the estimated average coefficient, as well as the $5 \%$ confidence interval computed for this coefficient (with the method "Lukacs" proposed by Lukacs et al. (2010)).

\subsection{Number of Events Per independent Variable (EPV):}

Biases tend to appear when the number of the least common event is small relatively to the number of variables. In our case, the scarcer event is always the choice of a lever (explained variable coded 1). In other terms, for a given type of measure, the choice of other types of measure (among the 8 remaining possibilities) is the most frequent event.

Vittinghoff and McCulloch (2007) suggest that the commonly recommended rule of 10 events (considering the scarcer one) per variable (Ottenbacher et al., 2004; Peduzzi et al., 1996) may often be too conservative. But a strict minimum of 5 events per variable seems to be relevant in order to avoid important bias. Hosmer et al. (2013, pp. 407-408) suggest that the 10 EPV rule is a good reference. Other characteristics of variables should also be taken into consideration (Courvoisier et al., 2011).

We will consider that the results can still be interpreted for 5 to $9 \mathrm{EPV}$, but unreliable under 5 EPV. Thus, the table below shows that the result cannot be reasonably interpreted for type of measure " 5 . Charter/code of conduct". For types of measure 7 and 8 , and to a lesser extent types of measure 3 and 6 , we don't consider to be in the "red zone", but we are aware of the additional uncertainty surrounding the related results.

Later works focused on specific types of measure within the Natura 2000 framework should adapt their sampling strategies in order to avoid this problem of event scarcity.

\footnotetext{
${ }^{15}$ For a given simulation. The bet is that the genetic algorithm will identify a similar pool of 100 best models across repeated simulations.
} 


\begin{tabular}{|c|c|c|c|c|c|c|c|c|c|}
\hline Type of measure (model) & 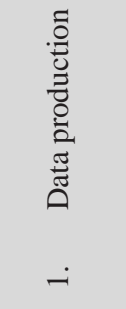 & 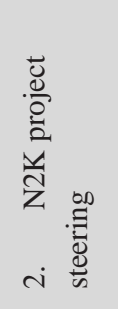 & 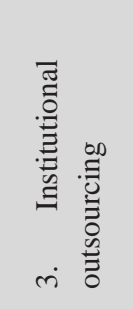 & 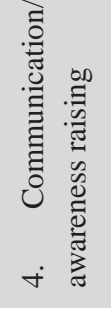 & 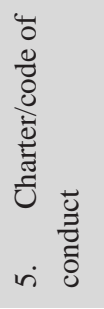 & 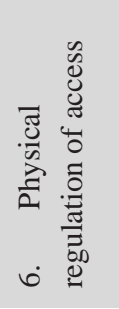 & 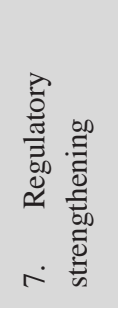 & 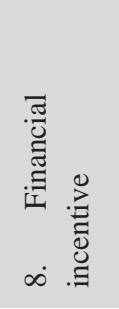 & 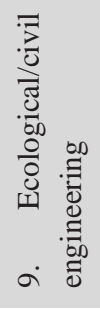 \\
\hline Number of positive events & 341 & 437 & 155 & 268 & 57 & 141 & 102 & 116 & 399 \\
\hline $\begin{array}{l}\text { Mean size of the models } \\
\text { (mean number of variables } \\
\text { included in the " } 100 \text { best } \\
\text { models") } \\
\text { [min; max] }\end{array}$ & $\begin{array}{c}18.8 \\
{[14 ; 23]}\end{array}$ & $\begin{array}{c}19.4 \\
{[13 ; 24]}\end{array}$ & $\begin{array}{c}16.2 \\
{[12 ; 22]}\end{array}$ & $\begin{array}{c}12.0 \\
{[8 ; 20]}\end{array}$ & $\begin{array}{c}15.9 \\
{[9 ; 22]}\end{array}$ & $\begin{array}{c}15.2 \\
{[10 ; 21]}\end{array}$ & $\begin{array}{c}16.2 \\
{[12 ; 23]}\end{array}$ & $\begin{array}{c}17.6 \\
{[13 ; 22]}\end{array}$ & $\begin{array}{c}15.1 \\
{[9 ; 23]}\end{array}$ \\
\hline $\begin{array}{l}\text { Mean size of model weighted } \\
\text { by model AIC-weight }\end{array}$ & 19.2 & 21.9 & 15.5 & 10.8 & 15.6 & 13.25 & 15.4 & 17.6 & 13.6 \\
\hline $\begin{array}{l}\text { Mean number of Events Per } \\
\text { Variable }\end{array}$ & 18.1 & 22.5 & 9.6 & 22.3 & 3.6 & 9.3 & 6.3 & 6.6 & 26.4 \\
\hline
\end{tabular}

\subsection{Use of AICc}

Burnham and Anderson (2002, p. 66) suggest that if the ratio N/K "number of individuals / number of variables" is less than 40 , one should use a second-order AIC.

Our complete model can include a maximum number of 61 variables, but as shown above, the 100 best models selected by glmulti are much smaller (less than 24 variables). Thus for our reference database ( $\mathrm{N}=1378$ individuals), the ratio $\mathrm{N} / \mathrm{K}$ could be as small as 22.6 , but in practice is always higher than 57.

However, we chose to use AICc (the corrected AIC) as a selection criterion, as this conservative approach was easily implemented under glmulti. For a model of 15 variables, the difference between AIC and AICc is of 0.352 (i.e. small relatively to the values of AICc obtained). We believe this issue is of minor importance.

\subsection{Multicollinearity : Variance Inflation Factor}

We examined the problem of multicollinearity through the criterion of the Variance Inflation Factor (VIF). For a given sample, the $\operatorname{VIF}^{16}$ of a variable $X_{i}$ is given by $\operatorname{VIF}_{i}=1 /\left(1-R_{i}{ }^{2}\right)$ where $R_{i}{ }^{2}$ is the multiple $R$-squared in the regression of $X_{i}$ by the other variables of the model $X_{j \neq i}$. It gives a continuous indication of the problem of multicollinearity for variable $\mathrm{X}_{\mathrm{i}}$. If $\mathrm{X}_{\mathrm{i}}$ is well explained by a linear regression on the other variables $\mathrm{X}_{\mathrm{j} \neq \mathrm{I}}$ (i.e. $\mathrm{Xi}$ is approximately a linear combination of $\mathrm{X}_{\mathrm{j} \neq \mathrm{i}}$.), $\mathrm{VIF}_{\mathrm{i}}$ grows towards infinity. An empirical rules of thumbs is that a VIF higher than 10 (or even 5) indicates a serious problem of multicollinearity (Gujarati, 2004, p. 366; James et al., 2013, pp. 101102).

\footnotetext{
${ }^{16}$ It indicates how much the variance of the corresponding estimated coefficient is inflated by the correlation with other variables (Gujarati, 2004, p. 218).
} 
For each of the 100 best models, we calculated the maximum VIF for the variables included $\left(\operatorname{Max}_{\text {variables }}(\mathrm{VIF})\right)$. Then we can calculate means, AIC-weighted means and maximum values of these 100 VIF. The table below shows that for all the types of measure, the 100 best models don't seem to exhibit strong problems of collinearity. The complete model (with say 60 variables) would present stronger problems of collinearity. But the process of variable selection reduces this problem by withdrawing variables with the smallest contribution to the explanatory power to the model.

\section{Summary values for the VIF among the glmulti 100 best models}

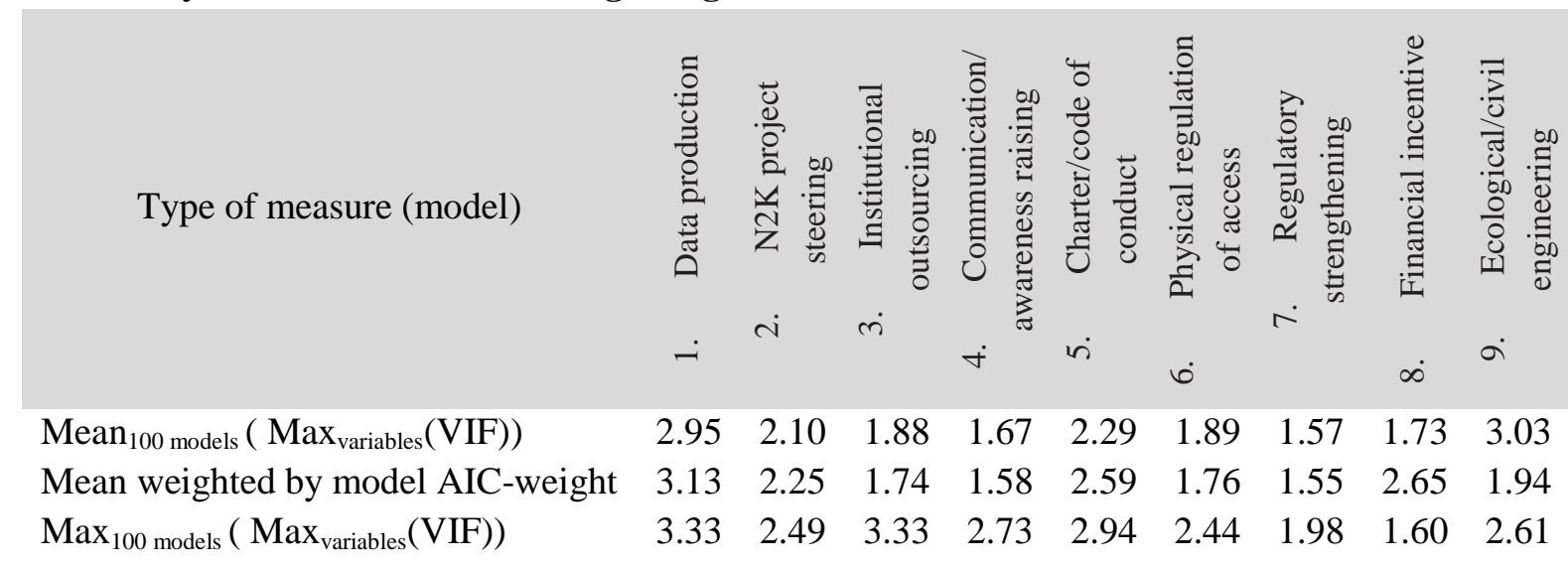

\subsection{Interaction terms}

Interaction terms were not included in the analysis. First for technical reasons : in its current version (version 1.0.7), glmulti can handle a maximum of 30 variables (including "single" variables or interactions). Second, because our variables are mainly seen as proxies. We considered that they were not precise enough to begin an exploration of interactions between detailed phenomena.

Interactions could subsequently be explored with new samples, through models confined to the most relevant variables identified by our results.

For the same reasons, more complex forms of variables (quadratic, logarithmic) were not explored either. 


\section{DIAGNOSTICS OF THE MODELS}

Readers are reminded that our model averaging methodology is based on an exploration of numerous potential explanatory models.

Even if the "complete model" would potentially include more than 60 independent variables, the principle of model selection and averaging is precisely to focus on the 100 "best", much smaller, models, and to compute average parameters out of them. The following results are based, for each type of measure, on these " 100 best models".

Most of the diagnostics presented below should generally be based on statistics computed with the outputs of one model, taking into account the "covariate patterns" among individuals. For the latter reason, it was complicated to work on the averaged-model provided by glmulti17. We worked on a model including all the variables which glmulti-importance was above 0.5. The fitted values of this model were highly correlated with the model-averaged fitted values (Pearson Correl. Coef. > 0.995). As such, this single model was deemed "representative" of the averaged model.

\subsection{Global significance of the models.}

Likelihood ratio test (Hosmer et al., 2013, p. 39)

$\mathrm{H} 0$ : all the coefficients are null (i.e. the model is not better than a constant) Performed with lrtest from package epicalc (R Core Team, 2013).

\begin{tabular}{|c|c|c|c|c|c|c|c|c|c|}
\hline $\begin{array}{l}\text { Type of } \\
\text { measure } \\
\text { (model) }\end{array}$ & 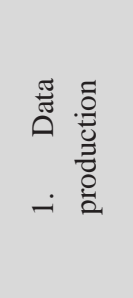 & 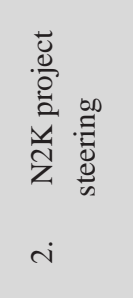 & 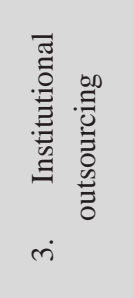 & 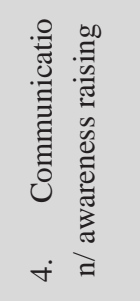 & 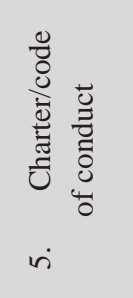 & 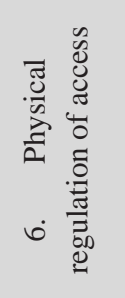 & 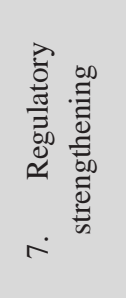 & 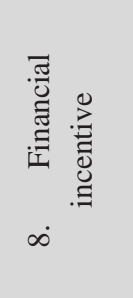 & 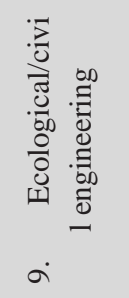 \\
\hline $\begin{array}{l}\text { G statistic } \\
\text { (difference } \\
\text { in } \\
\text { deviance) }\end{array}$ & $\begin{array}{c}105.476 \\
6\end{array}$ & $\begin{array}{c}156.346 \\
5\end{array}$ & $\begin{array}{c}135.08 \\
6\end{array}$ & $\begin{array}{c}105.433 \\
4\end{array}$ & $\begin{array}{c}54.560 \\
3\end{array}$ & $\begin{array}{c}97.594 \\
1\end{array}$ & $\begin{array}{c}81.073 \\
7\end{array}$ & $\begin{array}{c}126.08 \\
5\end{array}$ & $\begin{array}{c}192.701 \\
4\end{array}$ \\
\hline $\begin{array}{l}\text { Degrees of } \\
\text { freedom }\end{array}$ & 19 & 22 & 15 & 9 & 15 & 12 & 15 & 17 & 12 \\
\hline p-value & $5.4 \mathrm{e}-14$ & $3.1 \mathrm{e}-22$ & $2.1 \mathrm{e}-21$ & $1.2 \mathrm{e}-18$ & $2.1 \mathrm{e}-06$ & $1.6 \mathrm{e}-15$ & $4.4 \mathrm{e}-11$ & $1.1 \mathrm{e}-18$ & $1.0 \mathrm{e}-34$ \\
\hline
\end{tabular}

For all the models, we can reject with a high level of confidence the hypothesis that all the coefficients are null.

\subsection{Area under the ROC curve criterion}

Continuous indicator of the "model's ability to assign, in general, higher probabilities of the outcome to the subgroup who develop the outcome $(y=1)$ than it does to the subgroup who do not develop the outcome $(y=0)$ )" but not a goodness of fit indicator (Hosmer et al., 2013, p. 174).

Performed with auc from package pROC (R Core Team, 2013).

\footnotetext{
${ }^{17}$ Without going into the technical details, covariate patterns among individuals are not the same for the glmulti "100 best models" because the variables change for each model
} 


\begin{tabular}{|c|c|c|c|c|c|c|c|c|c|}
\hline Type of measure (model) & 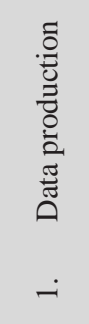 & 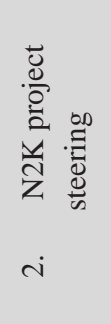 & 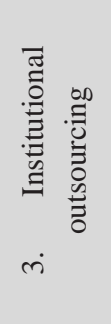 & 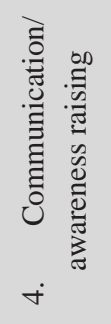 & 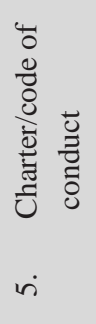 & 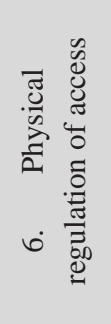 & 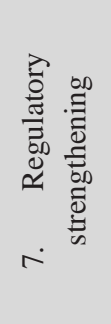 & 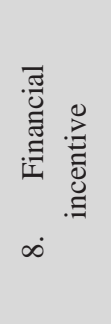 & 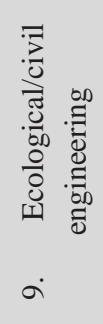 \\
\hline AUC & 0.67 & 0.704 & 0.759 & 0.684 & 0.76 & 0.734 & 0.744 & 0.804 & 0.725 \\
\hline
\end{tabular}

According to (Hosmer et al., 2013, p. 177), the discrimination of our models is acceptable (most of the AUC are between 0.7 and 0.8 ), except for models 1 and 4 for which it is considered poorer (though not terrible).

\subsection{Hosmer-Lemeshow test ( 10 deciles)}

Goodness of fit test : assesses if "the distances between observed and expected values be unsystematic and small, relative to the variation of the model" (Hosmer et al., 2013, p. 170)

The Hosmer-Lemeshow test is based on a division of individuals into deciles (or another number of groups) (Hosmer et al., 2013, p. 157). The summary statistic has a chi-square distribution with 10-2 $=8$ degrees of freedom.

Performed with hoslem.test from package ResourceSelection (R Core Team, 2013).

\begin{tabular}{|c|c|c|c|c|c|c|c|c|c|}
\hline Type of measure (model) & 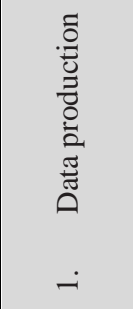 & 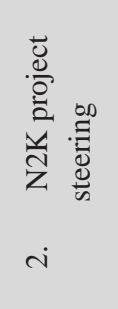 & 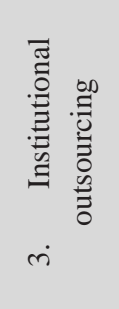 & 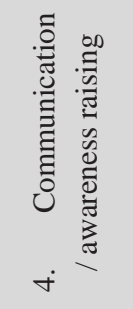 & 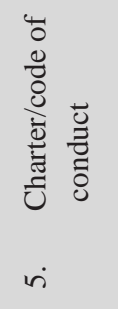 & 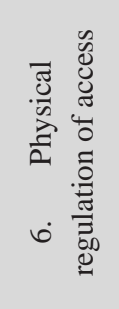 & 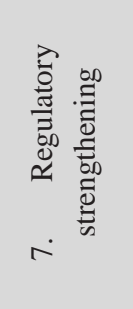 & 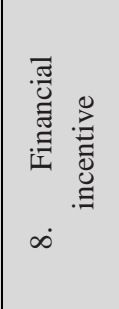 & 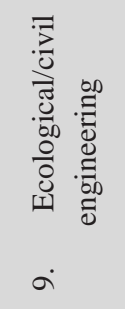 \\
\hline C_hat & 14.5532 & 9.3574 & 8.5806 & 10.7007 & 9.5696 & 7.0062 & 15.0084 & 8.5734 & 13.4491 \\
\hline Degree of freedom & 8 & 8 & 8 & 8 & 8 & 8 & 8 & 8 & 8 \\
\hline p-value & 0.06844 & 0.313 & 0.3789 & 0.2192 & 0.2965 & 0.536 & 0.05898 & 0.3796 & 0.0973 \\
\hline
\end{tabular}

\subsection{Osius and Rojek tests}

Adapted from (Osius and Rojek, 1992).

Goodness of fit test based on "a large sample normal approximation to the distribution of the Pearson chisquare statistic" (Hosmer et al., 2013, p. 164). The Pearson chi-square statistic is a sum of standardized residuals for the different covariate patterns (grouping of individuals presenting the same patterns of explanatory variables).

\begin{tabular}{|c|c|c|c|c|c|c|c|c|c|}
\hline Type of measure (model) & 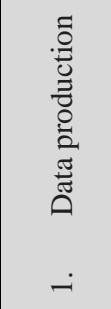 & 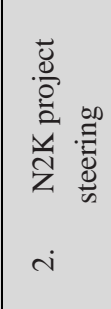 & 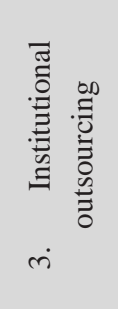 & 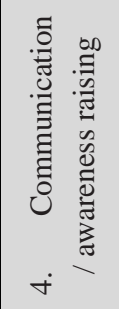 & 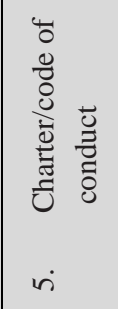 & 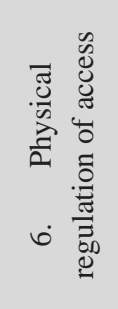 & 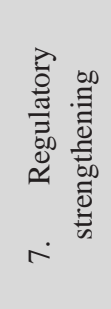 & 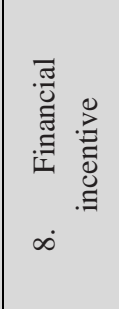 & 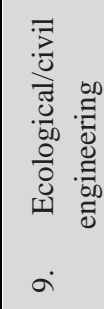 \\
\hline Statistic Pearson $\mathrm{z}_{\mathrm{X} 2}$ & 3.494 & 3.331 & -0.076 & 0.673 & 0.474 & -0.124 & 0.09 & 1.014 & 1.879 \\
\hline
\end{tabular}




\begin{tabular}{|l|l|l|l|l|l|l|l|l|l|}
\hline p-value $z_{x 2}$ & 0 & 0.001 & 0.939 & 0.501 & 0.636 & 0.901 & 0.928 & 0.311 & 0.06 \\
\hline Statistic Sum of squares $z_{S}$ & 2.232 & 2.671 & -0.16 & 0.632 & 0.395 & 0.094 & 0.026 & 0.09 & 0.705 \\
\hline p-value $z_{S}$ & 0.026 & 0.008 & 0.873 & 0.527 & 0.693 & 0.925 & 0.979 & 0.928 & 0.481 \\
\hline
\end{tabular}

Based on (Hosmer et al., 2013, p. 166) we decided to focus on the zS statistic. These tests would lead to reject the hypothesis of "goodness of fit" for the types of measure 1 and 2 . However, we consider that the poor results for these tests can be attributed to outliers (see part 4). Thus, we decided to consider our models as valid for a first approach.

\subsection{Stukel test}

(Hosmer et al., 2013, p. 166) based on (Stukel, 1988).

Not a goodness of fit statistics but "tests whether a generalized logistic model is better than a standard model fit to the data" (Hosmer et al., 2013, p. 164).

\begin{tabular}{|c|c|c|c|c|c|c|c|c|c|}
\hline Тур & 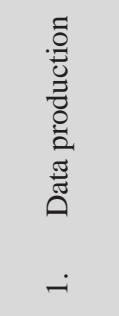 & 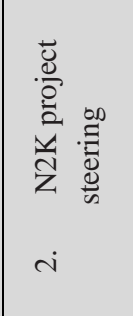 & 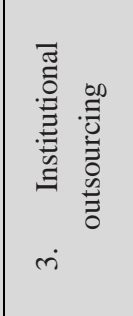 & 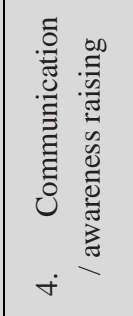 & 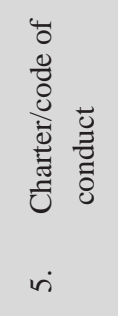 & 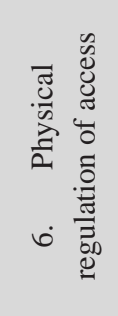 & 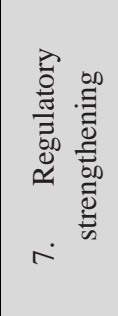 & 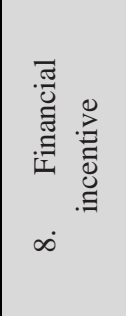 & 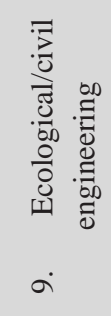 \\
\hline Statistic Stukel & -0.253 & -3.126 & -1.358 & -0.633 & -2.541 & -1.03 & -0.382 & -6.117 & -6.885 \\
\hline p-value Score test (Rao) & 0.881 & 0.21 & 0.507 & 0.729 & 0.111 & 0.597 & 0.826 & 0.047 & 0.032 \\
\hline
\end{tabular}

These tests suggest that generalized logistic models would be preferable for types of measure 8 and 9. This could be the object of future work.

\section{6. $\underline{R^{2} \text { measures }}$}

We provide here some " $\mathrm{R}^{2}$ equivalent measures" suggested by (Hosmer et al., 2013, pp. 182-185):

- Log-likelihood based $\mathrm{R}^{2}: \mathrm{R}_{\mathrm{L}}{ }^{2}$ (so called McFadden R-squared, or pseudo R-squared) (formula $5.18, \mathrm{p} 184)$

- Modified log-likelihood based $\mathrm{R}^{2}: \mathrm{R}_{\mathrm{LS}}{ }^{2}$ (formula 5.18, p184). This $\mathrm{R}^{2}$ can theoretically take the value 1.0 , contrarily to $\mathrm{R}_{\mathrm{L}}^{2}$.

- Pearson correlation coefficient for covariate patterns : $r_{c}{ }^{2}$ (Hosmer, Lemeshow, and Sturdivant 2013) (formula 5.14, p183)

- Linear regression like measure for covariate patterns : $\mathrm{R}_{\mathrm{ssc}}{ }^{2}$ (formula 5.15, p183)

- Linear regression like measure for covariate patterns, adjusted for small samples $R_{s s, a d j}{ }^{2}$ (formula 5.16, p183)

- Separation of probability distributions : CD (formula 5.20, p185)

\begin{tabular}{|c|c|c|c|c|c|c|c|c|c|}
\hline Type of measure (model) & 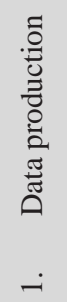 & 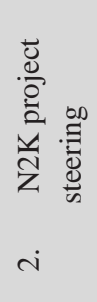 & 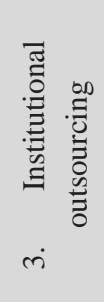 & 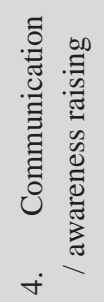 & 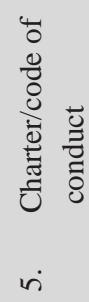 & 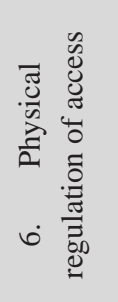 & 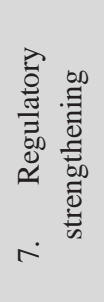 & 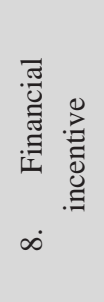 & 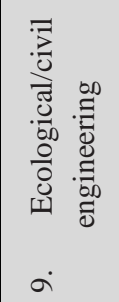 \\
\hline
\end{tabular}




\begin{tabular}{|l|l|l|l|l|l|l|l|l|l|}
\hline $\mathrm{R}_{\mathrm{L}}{ }^{2}$ (McFadden $\left.\mathrm{R}^{2}\right)$ & 0.068 & 0.091 & 0.139 & 0.078 & 0.114 & 0.107 & 0.111 & 0.158 & 0.116 \\
\hline $\mathrm{R}_{\mathrm{LS}}{ }^{2}$ & 0.097 & 0.121 & 0.193 & 0.107 & 0.140 & 0.155 & 0.16 & 0.284 & 0.154 \\
\hline $\mathrm{r}_{\mathrm{c}}{ }^{2}$ & 0.096 & 0.233 & 0.179 & 0.119 & 0.067 & 0.203 & 0.199 & 0.303 & 0.3 \\
\hline $\mathrm{R}_{\text {ssc }}{ }^{2}$ & 0.094 & 0.232 & 0.17 & 0.119 & 0.066 & 0.201 & 0.196 & 0.302 & 0.3 \\
\hline $\mathrm{R}_{\text {ssc,adj }}{ }^{2}$ & 0.081 & 0.22 & 0.161 & 0.113 & 0.054 & 0.194 & 0.187 & 0.293 & 0.294 \\
\hline $\mathrm{CD}$ & 0.079 & 0.111 & 0.12 & 0.085 & 0.053 & 0.082 & 0.077 & 0.111 & 0.131 \\
\hline
\end{tabular}

The so-called McFadden $\mathrm{R}^{2}$ is not recommended by (Mittlböck and Schemper, 1996). We give it here to show that other, more elaborated, measures can give a different picture of the global explanatory power of the model. 


\section{CHECKING FOR ROBUSTNESS}

During the building of our statistical methodology, we considered the possibility to modify the list of potential explanatory variables, or the size of our database. The former possibility was quite natural: by definition, the list of candidate variables is not given in an exploratory approach on models. The latter stemmed from the non-standardized nature of our material and the initial objective to classify all action-sheets within the same typology.

In other research perspectives, restrictions could have been applied to the database. For instance, one could have focused on actions conceptually aimed at modifying "Behaviors and practices" (types of measure 4 to 8). In this case, the database would have been shrunk (e.g. removal of "knowledge only" action-sheets), and variables expressing the type of uses targeted could have been included in the selection algorithm.

The identification of relevant variables for explanatory models, and their coefficients in the resulting models, can be affected by such subjective modifications of the database. We performed several simulations with different additions/removal of individuals/variables in order to assess the robustness of our results. The modifications applied may be considered as marginal. Thus, in our view, the assessed robustness is a strict minimum.

\begin{tabular}{|l|l|l|}
\hline \multicolumn{1}{|c|}{ Simulation } & \multicolumn{1}{c|}{$\begin{array}{c}\text { Size of the database } \\
\text { (nb of action-sheets) }\end{array}$} & \multicolumn{1}{c|}{ Description } \\
\hline Reference (BD3) & 1378 & All actions included \\
\hline $\begin{array}{l}\text { Averaging of more } \\
\text { models } \\
\text { (BD3 css200) }\end{array}$ & 1378 & $\begin{array}{l}\text { We average the 200 best models, instead of the } \\
100 \text { best models (with new "genetic exploration") } \\
\text { i.e. the parameter "confsetsize" of glmulti is set to } \\
\text { 200. }\end{array}$ \\
\hline $\begin{array}{l}\text { Modification of } \\
\text { variables (BD3 bis) }\end{array}$ & 1378 & $\begin{array}{l}\text { Includes the variables OPE_Engin.consult and } \\
\text { REGION_Bay.Biscay, and excludes the variables } \\
\text { OPE_Local.authority and TARGET_ND }\end{array}$ \\
\hline $\begin{array}{l}\text { Without outliers } \\
\text { (BD3_outlier20.) }\end{array}$ & 1354 to 1370 & $\begin{array}{l}\text { For each type of measure, outliers are identified } \\
\text { (with respect to the Reference model) and } \\
\text { withdrawn from the database }\end{array}$ \\
\hline $\begin{array}{l}\text { Marine } \\
\text { (BD3_marins) }\end{array}$ & 1390 & $\begin{array}{l}\text { Inclusion of two purely marine sites into the } \\
\text { database, and removal of the "terrestrial" } \\
\text { variables (Local social-economic characteristics) }\end{array}$ \\
\hline $\begin{array}{l}\text { Targeted } \\
\text { (BD3_ciblé) }\end{array}$ & 1276 & $\begin{array}{l}\text { Removal of actions with no mention of which } \\
\text { habitats/species are concerned by the action }\end{array}$ \\
\hline $\begin{array}{l}\text { Usages } \\
\text { (BD3_usages) }\end{array}$ & $\begin{array}{l}\text { Database shrunk to actions aimed at modifying } \\
\text { "Behaviors and practices". Only for types of } \\
\text { measure 4 to 8. }\end{array}$ \\
\hline
\end{tabular}

\footnotetext{
${ }^{18}$ See part 4.
} 


\section{REMOVAL OF OUTLIERS}

The removal of outliers is based on the simulation "BD3_bis" which presented better results for the diagnostics of the models.

Outliers are identified on the basis of detailed goodness-of-fit statistics. In order to compute these statistics, it was complicated to work on the averaged-model provided by glmulti (without going into the technical details, covariate patterns among individuals are not the same for the glmulti " 100 best models" because the variables change for each model). We worked on a model including all the variables which glmulti-importance was above 0.5 . The fitted values of this model were highly correlated with the model-averaged fitted values (Pearson Correl. Coef. > 0.995). As such, it was deemed representative of the averaged model.

The four graphs below correspond to the regression diagnostic plots for the type of measure 1 (M201) as suggested by (Hosmer et al., 2013, pp. 193-196). Here, we considered that 4 covariate patterns (red circles) can be considered as outliers.
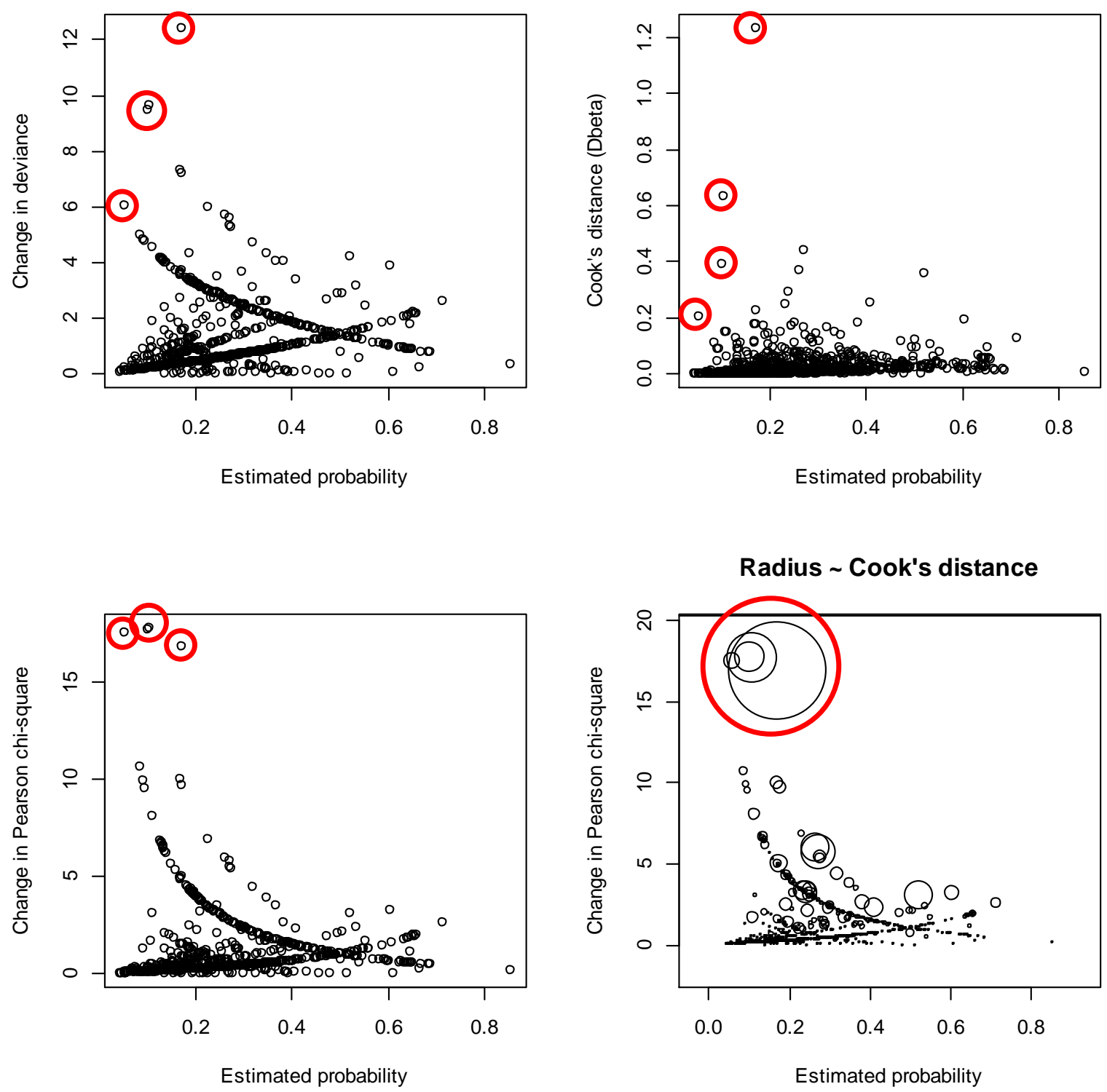

A summary of the number of outliers removed for each model and of their "nature" is given in the following table : 


\begin{tabular}{|c|c|c|c|c|c|c|c|c|c|}
\hline Type of measure (model) & 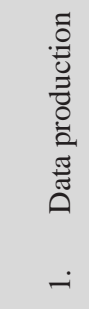 & 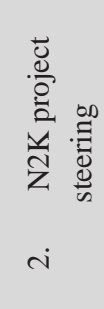 & 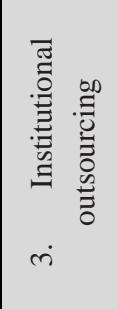 & 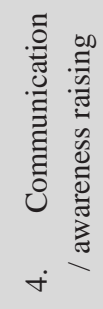 & 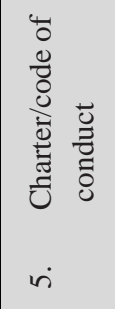 & 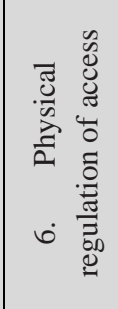 & 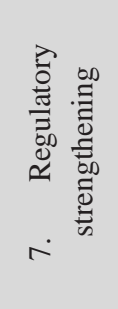 & 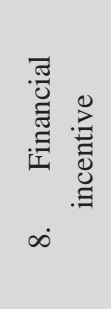 & 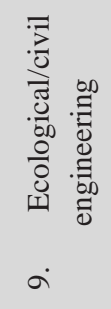 \\
\hline $\begin{array}{l}\text { Number of outliers } \\
\text { (patterns) removed }\end{array}$ & 4 & 7 & 6 & 8 & $\begin{array}{l}\text { Not } \\
\text { done }\end{array}$ & $6(9)$ & 6 & 8 & 6 \\
\hline $\begin{array}{l}\text { Of which Pearson's chi-square } \\
\text { outliers }\end{array}$ & 4 & 5 & 5 & 5 & & $6(9)$ & 4 & 5 & 3 \\
\hline Of which Cook's distance outliers & 0 & 3 & 1 & 3 & & 0 & 2 & 3 & 4 \\
\hline $\begin{array}{l}\text { Number of outliers } \\
\text { (actions) removed }\end{array}$ & 19 & 22 & 8 & 19 & $\begin{array}{l}\text { Not } \\
\text { done }\end{array}$ & $\begin{array}{l}10 \\
(14)\end{array}$ & 13 & 21 & 24 \\
\hline
\end{tabular}

Summary of results for simulation BD3_bis:

\begin{tabular}{|c|c|c|c|c|c|c|c|c|c|}
\hline Type of measure (model) & 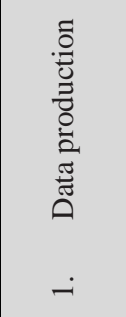 & 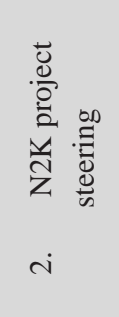 & 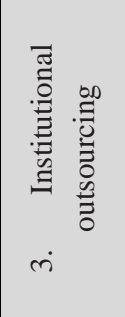 & 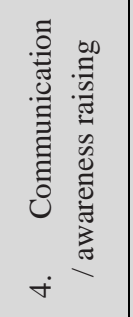 & 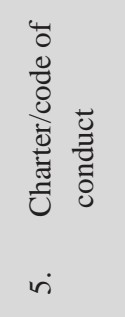 & 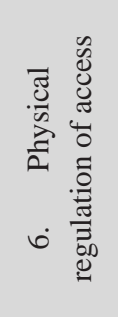 & 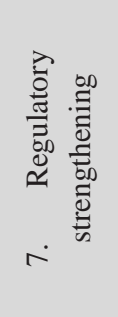 & 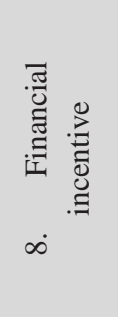 & 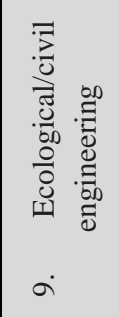 \\
\hline Area Under the Curve & 0.679 & 0.715 & 0.759 & 0.684 & 0.736 & 0.727 & 0.756 & 0.806 & 0.728 \\
\hline \multicolumn{10}{|c|}{ Hosmer-Lemeshow test } \\
\hline C_hat & 7.021 & 4.959 & 7.056 & 10.701 & 11.551 & 7.542 & 5.090 & 7.316 & 9.678 \\
\hline $\mathrm{p}$-value $(\mathrm{g}=10,8 \mathrm{df})$ & 0.534 & 0.762 & 0.531 & 0.219 & 0.172 & 0.479 & 0.748 & 0.503 & 0.288 \\
\hline \multicolumn{10}{|c|}{ Stukel test } \\
\hline Statistique Stukel Rao & -0.106 & -0.617 & -1.412 & -0.633 & -3.949 & -0.739 & -0.424 & -6.872 & -6.712 \\
\hline p-value & 0.948 & 0.735 & 0.494 & 0.729 & 0.047 & 0.39 & 0.809 & 0.032 & 0.035 \\
\hline \multicolumn{10}{|c|}{ Osius-Rojek test } \\
\hline Statistique Pearson $\mathrm{z}_{\mathrm{S}}$ & 1.891 & 2.912 & -0.228 & 0.632 & 0.62 & -0.135 & -0.078 & 0.474 & 0.662 \\
\hline $\mathrm{p}$-value $\mathrm{z}_{\mathrm{S}}$ & 0.059 & 0.004 & 0.82 & 0.527 & 0.535 & 0.893 & 0.938 & 0.635 & 0.508 \\
\hline \multicolumn{10}{|c|}{$\mathbf{R}^{2}$ measures } \\
\hline $\mathrm{R}_{\mathrm{L}}^{2}\left(\right.$ McFadden $\left.\mathrm{R}^{2}\right)$ & 0.073 & 0.103 & 0.141 & 0.078 & 0.096 & 0.103 & 0.118 & 0.162 & 0.119 \\
\hline $\mathrm{R}_{\mathrm{LS}}{ }^{2}$ & 0.103 & 0.136 & 0.195 & 0.107 & 0.131 & 0.228 & 0.173 & 0.211 & 0.158 \\
\hline$r_{c}^{2}$ & 0.119 & 0.234 & \begin{tabular}{|l|}
0.187 \\
\end{tabular} & \begin{tabular}{|l|}
0.119 \\
\end{tabular} & 0.062 & 0.351 & 0.208 & 0.214 & 0.305 \\
\hline $\mathrm{R}_{\mathrm{ssc}}^{2}$ & 0.118 & 0.234 & \begin{tabular}{|l|}
0.179 \\
\end{tabular} & \begin{tabular}{|l|}
0.119 \\
\end{tabular} & 0.056 & 0.349 & 0.206 & 0.213 & 0.305 \\
\hline $\mathrm{R}_{\mathrm{ssc}, \mathrm{adj}}{ }^{2}$ & 0.105 & 0.22 & 0.169 & 0.113 & 0.047 & 0.344 & 0.197 & 0.203 & 0.297 \\
\hline $\mathrm{CD}$ & 0.085 & 0.126 & 0.121 & 0.085 & 0.046 & 0.079 & 0.08 & 0.112 & 0.135 \\
\hline
\end{tabular}

Summary of results for simulation BD3_bis without outliers: 


\begin{tabular}{|c|c|c|c|c|c|c|c|c|c|}
\hline Type of measure (model) & 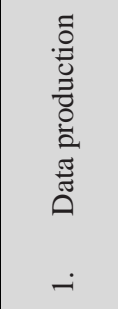 & 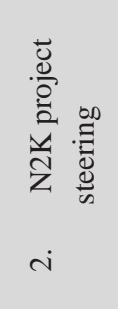 & 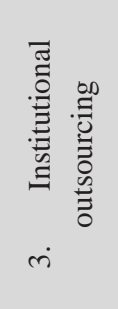 & 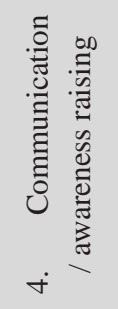 & 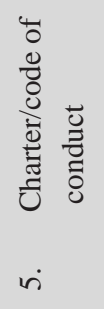 & 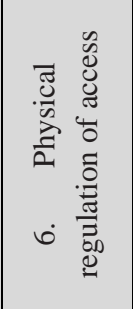 & 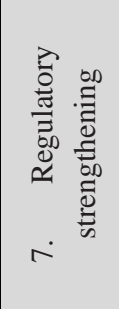 & 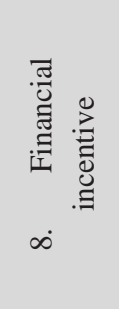 & 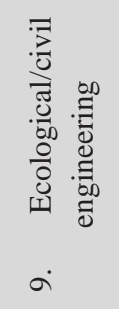 \\
\hline Area Under the Curve & 0.693 & 0.723 & 0.78 & 0.693 & & 0.76 & 0.788 & 0.823 & 0.736 \\
\hline \multicolumn{10}{|c|}{ Hosmer-Lemeshow test } \\
\hline C_hat & 5.478 & 4.936 & 9.755 & 2.068 & & 15.289 & 3.580 & 4.680 & 9.634 \\
\hline $\mathrm{p}$-value $(\mathrm{g}=10,8 \mathrm{df})$ & 0.706 & 0.766 & 0.283 & 0.979 & & 0.054 & 0.893 & 0.791 & 0.292 \\
\hline \multicolumn{10}{|c|}{$\underline{\text { Stukel test }}$} \\
\hline Statistique Stukel Rao & -0.767 & -0.749 & -4.592 & -0.668 & & -2.867 & -4.099 & -1.746 & -9.407 \\
\hline p-value & 0.682 & 0.688 & 0.101 & 0.716 & & 0.238 & 0.129 & 0.418 & 0.009 \\
\hline \multicolumn{10}{|c|}{ Osius-Rojek test } \\
\hline Statistique Pearson $\mathrm{z}_{\mathrm{S}}$ & 0.224 & 1.559 & -0.12 & 0.388 & & -0.047 & -0.714 & 0.114 & 0.262 \\
\hline $\mathrm{p}$-value $\mathrm{z}_{\mathrm{S}}$ & 0.823 & 0.119 & 0.904 & 0.698 & & 0.963 & 0.475 & 0.909 & 0.794 \\
\hline \multicolumn{10}{|c|}{$\mathbf{R}^{2}$ measures } \\
\hline $\mathrm{R}_{\mathrm{L}}^{2}\left(\mathrm{McF}\right.$ adden $\left.\mathrm{R}^{2}\right)$ & 0.087 & 0.111 & 0.155 & 0.088 & & 0.131 & 0.143 & $0.689 *$ & 0.132 \\
\hline $\mathrm{R}_{\mathrm{LS}}{ }^{2}$ & 0.122 & 0.149 & 0.216 & 0.117 & & 0.203 & 0.334 & $0.758^{*}$ & 0.172 \\
\hline$r_{c}^{2}$ & 0.173 & 0.246 & 0.197 & 0.122 & & 0.251 & 0.418 & 0.237 & 0.328 \\
\hline $\mathrm{R}_{\mathrm{ssc}}{ }^{2}$ & 0.173 & 0.246 & 0.184 & 0.122 & & 0.25 & 0.417 & 0.236 & 0.328 \\
\hline $\mathrm{R}_{\mathrm{ssc}, \mathrm{adj}}{ }^{2}$ & 0.16 & 0.233 & 0.175 & 0.115 & & 0.244 & 0.41 & 0.226 & 0.321 \\
\hline
\end{tabular}

*High values due to the absence of intercept in the model

The results above show that the removal of a few outliers lead to better results in terms of goodness of fit. The need for a generalized logistic model is confirmed for the type of measure 9, but the fit of the model is deemed good.

The number of outliers to be removed is quite arbitrary. If we had considered that 3 more covariate patterns should have been removed from the $6^{\text {th }}$ model, it would have got a slightly better Area Under the Curve and would have "passed all the tests". 


\section{GENERAL CONCLUSION}

In brief, the statistics presented in part B show that the global explanatory power of our models is significant but not tremendous. This is not very surprising. The initial quality of our explained variables was rather poor. Our material was not standardized, and sometimes was not very precise in its descriptions. The typology used to standardize this material was both practical and conceptual. As such, categories can encompass administrative instruments of different nature that don't follow the same logic. Besides, our explanatory variables were in some cases of admittedly poor precision and best seen as "thick" proxies of complex realities.

More detailed variables, focused on more specific questions, would probably get better performances. We hope that our first results can help subsequent research approaches to explore more thoroughly some variables, including potentially relevant confounding factors, or to compare local results to more general trends.

However, we show in part 4 that the statistics of part B are heavily dependent on the presence of a handful of "outliers". The results of the analysis (selected models) are not radically modified when these outliers are removed from the database. But the statistical tests are much reassuring.

Given the role of outliers, given that we take into account different simulations in order to ensure a minimal robustness, and given that our data confirm some of the most expectable results, we consider that the general results of our models are reliable and are worthy of commentaries. 


\section{REFERENCES}

Burnham, K.P., Anderson, D.R., 2002. Model Selection and Multimodel Inference: A Practical Information-Theoretic Approach. Springer Science \& Business Media, New-York.

Burnham, K.P., Anderson, D.R., Huyvaert, K.P., 2011. AIC model selection and multimodel inference in behavioral ecology: some background, observations, and comparisons. Behav. Ecol. Sociobiol. 65, 23-35. doi:10.1007/s00265-010-1029-6

Calcagno, V., De Mazancourt, C., 2010. glmulti: An R Package for Easy Automated Model Selection with (Generalized) Linear Models. J. Stat. Softw. 34.

Courvoisier, D.S., Combescure, C., Agoritsas, T., Gayet-Ageron, A., Perneger, T.V., 2011. Performance of logistic regression modeling: beyond the number of events per variable, the role of data structure. J. Clin. Epidemiol. 64, 993-1000. doi:10.1016/j.jclinepi.2010.11.012

Garamszegi, L.Z., 2011. Information-theoretic approaches to statistical analysis in behavioural ecology: an introduction. Behav. Ecol. Sociobiol. 65, 1-11. doi:10.1007/s00265-010-1028-7

Gujarati, D.N., 2004. Econométrie, 1ère édition. ed, Ouverture économiques. De Boeck, Bruxelles.

Hosmer, D.W., Lemeshow, S., Sturdivant, R.X., 2013. Applied logistic regression, 3rd ed, Wiley Series in Probability and Statistics. Wiley.

James, G., Witten, D., Hastie, T., Tibshirani, R., 2013. An Introduction to Statistical Learning with Applications in R, Springer. ed, Springer Texts in Statistics. New York.

Lukacs, P.M., Burnham, K.P., Anderson, D.R., 2010. Model selection bias and Freedman's paradox. Ann. Inst. Stat. Math. 62, 117-125. doi:10.1007/s10463-009-0234-4

Mittlböck, M., Schemper, M., 1996. Explained variation for logistic regression. Stat. Med. 15, 19871997. doi:10.1002/(SICI)1097-0258(19961015)15:19<1987::AID-SIM318>3.0.CO;2-9

Osius, G., Rojek, D., 1992. Normal Goodness-of-Fit Tests for Multinomial Models with Large Degrees of Freedom. J. Am. Stat. Assoc. 87, 1145-1152. doi:10.2307/2290653

Ottenbacher, K.J., Ottenbacher, H.R., Tooth, L., Ostir, G.V., 2004. A review of two journals found that articles using multivariable logistic regression frequently did not report commonly recommended assumptions. J. Clin. Epidemiol. 57, 1147-1152.

doi:10.1016/j.jclinepi.2003.05.003

Peduzzi, P., Concato, J., Kemper, E., Holford, T.R., Feinstein, A.R., 1996. A simulation study of the number of events per variable in logistic regression analysis. J. Clin. Epidemiol. 49, 13731379. doi:10.1016/S0895-4356(96)00236-3

Pinton, F., Alphandéry, P., Billaud, J.-P., Deverre, C., Fortier, A., Géniaux, G., 2006. La construction du réseau Natura 2000 en France, L'environnement en question. La Documentation française, Paris.

Posada, D., Buckley, T.R., 2004. Model Selection and Model Averaging in Phylogenetics: Advantages of Akaike Information Criterion and Bayesian Approaches over Likelihood Ratio Tests. Syst. Biol. 53, 793-808.

R Core Team, 2013. R: A language and environment for statistical computing. R Foundation for Statistical Computing. Vienna, Austria.

Sanharawi, M. El, Naudet, F., 2013. Comprendre la régression logistique. J. Fr. Ophtalmol. 36, 710715. doi:10.1016/j.jfo.2013.05.008 
Stukel, T.A., 1988. Generalized Logistic Models. J. Am. Stat. Assoc. 83, 426-431. doi:10.1080/01621459.1988.10478613

Symonds, M.R.E., Moussalli, A., 2011. A brief guide to model selection, multimodel inference and model averaging in behavioural ecology using Akaike's information criterion. Behav. Ecol. Sociobiol. 65, 13-21. doi:10.1007/s00265-010-1037-6Vittinghoff, E., McCulloch, C.E., 2007. Relaxing the rule of ten events per variable in logistic and Cox regression. Am. J. Epidemiol. 165, 710-718. doi:10.1093/aje/kwk052 